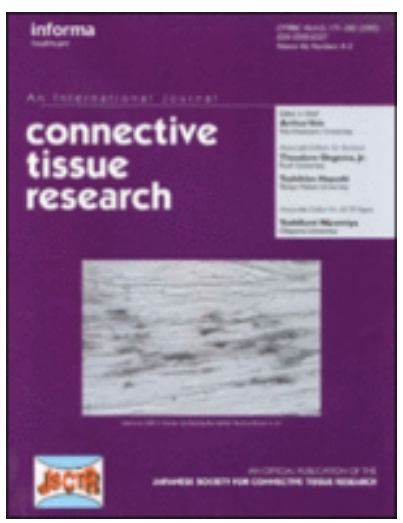

\title{
Marrow aspiration in aged mice: intramedullary osteogenesis, reduced mechano-adaptation, increased marrow fat
}

\begin{tabular}{|r|l|}
\hline Journal: & Connective Tissue Research \\
\hline Manuscript ID & GCTS-2019-0208.R2 \\
\hline Manuscript Type: & Original Research \\
\hline Dute Submitted by the & $21-$ Nov-2019 \\
\hline Complete List of Authors: & $\begin{array}{l}\text { Piet, Judith; Northeastern University, Bioengineering } \\
\text { Adamo, Sarah; Northeastern University, Bioengineering } \\
\text { Hu, Dorothy; Harvard School of Dental Medicine, Oral medicine, infection } \\
\text { and immunity } \\
\text { Baron, Rolan; Harvard Medical School, Medicine; Harvard School of } \\
\text { Dental Medicine, Oral medicine, infection and immunity } \\
\text { Shefelbine, Sandra; Northeastern University, Mechanical and Industrial } \\
\text { Engineering, Bioengineering }\end{array}$ \\
\hline Keywords: & $\begin{array}{l}\text { bone adaptation, tibial loading, marrow aspiration, histomorphometry, } \\
\text { BMAT }\end{array}$ \\
\hline
\end{tabular}

\section{SCHOLARONE ${ }^{\text {M }}$ Manuscripts}




\title{
Marrow aspiration in aged mice: intramedullary osteogenesis,
}

\section{reduced mechano-adaptation, increased marrow fat}

Judith Piet $^{1}$, Sarah Adamo ${ }^{1}$, Dorothy Hu${ }^{3}$, Roland Baron ${ }^{3}$, Sandra J. Shefelbine ${ }^{1,2}$

${ }^{1}$ Department of Bioengineering, Northeastern University, Boston, MA 02115, USA

${ }^{2}$ Department of Mechanical and Industrial Engineering, Northeastern University, Boston, MA 02115, USA

3 Department of Medicine, Harvard Medical School, and Division of Bone and Mineral Research, and Department of Oral Medicine, Infection and Immunity, Harvard School of Dental Medicine, Boston, MA 02115, USA

\author{
Corresponding Author: \\ Dr. Sandra J. Shefelbine \\ Department of Bioengineering \\ Northeastern University \\ 805 Columbus Avenue \\ Boston MA 02120 \\ email: s.shefelbine@northeastern.edu
}




\section{Declarations of interest: none}

\section{Abstract}

3 With age, the number of adipocytes and osteoclasts increases, the number of osteoblasts decreases, and

4 mechano-adaptation is impaired. Using marrow aspiration, which has a known osteogenic effect in young

5 mice, we sought to recruit osteoblast progenitors to mediate the mechano-adaptive response to in vivo

6 tibial loading. First, we assessed bone formation and marrow adiposity in the tibiae of old mice $(>20$

7 months) sacrificed 1, 2, and 4 weeks after unilateral marrow aspiration. Then, we examined the effects of

8 marrow aspiration on mechano-adaptation in aged mice using tibial loading. Two weeks after aspiration,

9 aspirated tibiae had more bone than contralateral tibiae due to the formation of bone in the medullary

10 canal. Two weeks and four weeks after marrow aspiration, the volume of marrow adipose tissue was

11 higher in the aspirated tibiae, compared to contralateral tibiae. Histomorphometry indicated that

12 aspiration increased non-periosteal (endosteal, intracortical, intramedullary) bone formation, compared to

13 the contralateral tibia. Mice with marrow aspiration had reduced periosteal bone formation in the

14 contralateral tibia, compared to mice that had loading alone. Loading-induced periosteal bone formation

15 was higher in mice that had loading alone, compared to mice that had aspiration + loading, indicating that

16 aspiration further reduced the mechano-adaptive response. These data demonstrate that, in old mice, bone

17 forms in the medullary canal following aspiration. Adiposity is increased following marrow aspiration,

18 and periosteal mechano-adaptation is reduced. 


\section{Keywords}

21 Marrow aspiration, BMAT, tibial loading, bone adaptation, histomorphometry

22

23 Running head: "Marrow aspiration in aged mice"

24

25 This research received internal funding from Northeastern University.

26

27 


\section{Introduction}

29 Bone is a dynamic tissue that adapts to external loads. Reduced loads promote bone resorption by osteoclasts, moderate loads maintain bone mass, and high loads promote bone formation by osteoblasts. In vivo uniaxial tibial loading is a common model used to study mechano-adaptation in mice. While mice are under anesthesia, the tibia is fixed in loading cups at the ankle and knee and subjected to cyclic compressive loads. This loading is in near-physiological direction and promotes bone formation in the cortical and trabecular compartments, which can be evaluated with dynamic histomorphometry and quantitative micro-CT imaging [1,2]. Increasing cycle repetitions and load magnitude further augments bone formation. Bone's adaptive response to in vivo tibial loading model is reduced in aged mice,

37 compared to young and mature mice. In aged bone, higher strain magnitudes are required to promote a mechano-adaptive response [3-5]. Among many other changes in bone biology with aging, the shift in cell populations is suspected to impair the mechano-adaptive response. With age, the number and activity of osteoclasts is increased [6-8]. Concurrently, progenitor cells tend to differentiate into adipocytes rather than cells of the osteoblastic lineage [9-11], and the number and activity of osteoblasts is decreased [12-

$4215]$.

The present work aims to prime old bone to mediate a stronger mechano-adaptive response, by utilizing the cells recruited in response to bone marrow aspiration. In young mice, marrow ablated by aspiration, reaming, or flushing, is regenerated within weeks (4 weeks in 6-8 week-old mice [16]). The transient

47 formation and resorption of intramembranous bone in the medullary canal, which takes place after 48 marrow ablation, has been thoroughly characterized (in rats [17], in mice [18]). Briefly, the response to marrow injury/aspiration in the medullary canal is the following: clot formation, capillary invasion, appearance of mesenchymal stem cells and then differentiation to osteoblasts, formation of intramembranous bone, reappearance of hematopoietic tissue, and finally bone resorption by osteoclasts.

52 Systemic bone formation (not restricted to the ablated bone) has been observed (in rats [19]). This model 
53 is widely used in young (and rarely in mature) rodents because it is highly reproducible, and because it

54 gives the opportunity to study how different factors are involved bone formation and resorption in vivo, 55 within a short time period.

56

57 Few studies have looked at the effects of marrow aspiration in skeletally mature rodents (rats [20-22],

58 mice [23]). In 24-month-old rats, the number of osteoblasts and the volume of mineralized bone was

59 lower compared to 6-month-old rats [20]. To our knowledge, no study has examined the potential

60 osteogenic effects of marrow aspiration and the subsequent effects on mechano-adaptation in old

61 osteoporotic mice (over 20 months of age).

62

63 The first objective of this study is to characterize the response of old murine bone to marrow aspiration,

64 by quantifying the amount of bone and marrow adipose tissue following marrow ablation. We

65 hypothesize that even in aged animals, bone forms in the medullary canal in response to marrow

66 aspiration. The second objective of this study is to examine the effects of marrow aspiration on bone

67 mechano-adaptation, with the rationale that cells recruited following aspiration can mediate the mechano-

68 adaptive response. We hypothesize that marrow aspiration augments the mechano-adaptive response of 69 aged bone.

70

71 


\section{2. Materials and methods}

\section{$73 \quad 2.1$ Animals}

74 Female C57BL/6J retired breeders were obtained from Jackson Laboratory at 6-9 months of age, and aged 75 until 20-23 months old. Mice were housed in groups of five (individually ventilated cages, sterilized corn 76 cob bedding with sterilized nestlets and Enviro-Dri), with a 12-hour light/dark cycle, and fed maintenance 77 mouse diet (Iso-Pro RMH 3000 and filtered water). All animal procedures received approval from 78 Northeastern University's Institutional Animal Care and Use Committee (IACUC, project 18-0105R).

79 All live animal experiments were performed in the animal facility at Northeastern University. Over the 80 course of the experiment, animal welfare was assessed daily (external appearance, abnormal activity, 81 answer to external stimulation, weight, body condition score).

82 Mice were randomly allocated to 6 different groups (Figure 1B and Figure 2B): (1) marrow aspiration, 83 sacrifice after 1 week $(n=5) ;(2)$ marrow aspiration, sacrifice after 2 weeks $(n=7)$; (3) marrow aspiration, 84 sacrifice after 4 weeks $(n=7)$; (4) marrow aspiration, sacrifice after 6 weeks $(n=7)$; (5) loading for 2 85 weeks ( $\mathrm{n}=7)$; (6) marrow aspiration, followed after 4 weeks by 2 weeks of tibial loading ( $\mathrm{n}=8)$ (see 86 weights in supplementary table S1). Sample sizes were based on a previous study from our group using

87 tibial loading in old mice, which indicated that 5 mice per group were needed to obtain statistical 88 significance with histomorphometric assessment [24], and groups with a longer experimental time were 89 assigned additional mice in case of animals dying due to old age. Groups 1-3 examined the osteogenic 90 and adipogenic response to marrow aspiration, and groups 4-6 examined the effects of marrow aspiration 91 on mechano-adaptation. Experiments in the 6 groups were run in parallel to minimize age difference at 92 sacrifice, and samples were assessed at the same time.

\subsection{Tibial marrow aspiration}

94 On day 0 , at 20-23 months of age, mice were anesthetized with 5\% isoflurane, the advantages of 95 inhalation anesthesia being that anesthesia depth is easy to steer, metabolization is limited, are recovery is 96 fast. Mice were kept on a warm pad during surgery, and later during recovery. The right hindlimb 
97 underwent marrow aspiration (Figure 1A) [18]. A small incision was performed on the skin that covers 98 the knee (about $2 \mathrm{~mm}$ in length). The $25 \mathrm{~g}$ needle of a saline-filled syringe was inserted into the tibial 99 cavity, under the patella, parallel to the longitudinal axis of the tibia. The motion of the saline exiting the needle locally disrupted the marrow. The plunger was moved back to create negative pressure, to aspirate bone marrow (reddish coloration in the syringe). This operation was repeated with clean saline-filled 102 syringes that had a smaller diameter $(28.5 \mathrm{~g})$ to minimize damage to the needle track. Saline was gently 103 pushed into the tibial cavity and aspirated, until the liquid aspirated came out clear (using overall $2 \mathrm{~mL}$ of saline). After aspiration, the skin of the knee was closed with Monocryl sutures and Vetbond. The analgesic drug Meloxicam (NSAID, $5 \mathrm{mg} / \mathrm{kg} /$ day, recommended dosage in mice) was administered subcutaneously once a day until day 3 . This procedure did not achieve total aspiration of the marrow, in particular the distal end of the tibia was not reached by the needle because of the tibial curvature, but it achieved a reproducible injury to the proximal end of the marrow.

\subsection{In vivo tibial loading}

110 Groups 4 $\underline{5}$ and 5-6 were subjected to in vivo tibial loading, 3 times a week for 2 weeks using an Instron 1115942 , starting 4 weeks after marrow aspiration for group $5 \underline{6}$. Mice were anesthetized with 3\% isoflurane.

112 The right ankle and knee were fixed in custom-made loading cups and held with a preload of $1.5 \mathrm{~N}$, and

113 loading was applied vertically through the knee (Figure 2A). The right tibia was subjected to 100

114 compressive cycles, with a magnitude of $9 \mathrm{~N}$, a rise and unloading rate of 20-30 N/s, and a $1 \mathrm{~s}$ rest period inserted between each cycle. This loading protocol induced small but significant bone formation in aged mice in a previous study (20-22 months, [24]).

\section{$117 \quad 2.4$ Fluorochrome labeling for dynamic histomorphometry}

118 Mice in groups 4-6 were injected with a dose of $20 \mathrm{mg} / \mathrm{kg}$ calcein (Sigma C0875) intraperitoneally on two consecutive days, 2 weeks before sacrifice, and with a dose of $40 \mathrm{mg} / \mathrm{kg}$ demeclocycline (Sigma D6140) and $10 \mathrm{mg} / \mathrm{kg}$ calcein on two consecutive days before sacrifice (see * on Figure $2 \mathrm{~B}$ ), in order to quantify 
121 the amount of bone formed over the last two weeks of the experiment (standard protocol at Harvard

122 School of Dental Medicine, e.g. used in [24]).

\section{$123 \quad 2.5$ Sacrifice and tibiae fixation}

124 Mice were sacrificed by $\mathrm{CO}_{2}$ inhalation and cervical dislocation (see weights at sacrifice in

125 supplementary table S1). Tibiae in groups 1, 2, and 3, were dissected from the surrounding muscles, and

126 fixed in $10 \%$ neutral buffered formalin. In groups 4, 5, and 6, surrounding muscles were kept to preserve

127 periosteal surfaces for histomorphometry, and fixed in $70 \%$ ethanol.

\section{$128 \quad 2.6$ Calcified scans}

129 Calcified samples were imaged in a desktop micro-CT scanner (Scanco $\mu$ CT40, $10 \mu \mathrm{m}$ isotropic voxel 130 size, $70 \mathrm{kVp}, 114 \mu \mathrm{A}, 8 \mathrm{~W}, 200 \mathrm{~ms}$ ). The portion of tibia located between the tibia-fibula junctions was 131 analyzed, as the most distal part was not reached by marrow aspiration. Tibia-fibula junctions were 132 defined as the locations where the tibia and the fibula split on micro-CT images (approximately $10 \%$ and $13360 \%$ of total tibial length). Bone cross-sectional area along that portion was obtained using the BoneJ 134 plugin in ImageJ [25] (threshold $=4,500)$.

135 In each pair of tibiae, intramedullary bone was segmented out from cortical bone using Mimics (see 136 Figure 1C and Figure 2C). Intramedullary bone was defined as bone present inside the medullary canal, 137 which did not have the typical structure of the very few trabeculae present in old mice (Figure 3).

\subsection{Osmium staining and imaging}

139 After scanning the calcified bones, tibiae in groups 1, 2, and 3, were decalcified for 21 days in a $4 \%$

140 EDTA solution, and were then incubated for 4 days in a $1 \%$ osmium tetroxide solution as described in

141 [26]. Osmium tetroxide fixes into lipid and is radio-opaque, therefore allowing the visualization of 142 adipocytes after micro-CT imaging. Following osmium staining, decalcified bones were imaged in a 143 desktop micro-CT (Scanco $\mu \mathrm{CT} 40,10 \mu \mathrm{m}$ isotropic voxel size, $55 \mathrm{kVp}, 145 \mu \mathrm{A}, 8 \mathrm{~W}, 300 \mathrm{~ms}$ ). Osmium 144 also stains remaining bits of soft tissue, so adipose volume (stained by osmium) was segmented in 145 Mimics to ensure no stain outside the marrow cavity would be included (see Figure $1 \mathrm{C}$, threshold = 
146 20,928), and quantified with BoneJ. The volume between tibia-fibula junctions was analyzed, as the distal 147 part is always filled with constitutive adipose tissue in mice (as opposed to "regulated" adipose tissue in 148 the proximal end [27]). 2 animals were excluded because muscle dissection was incomplete in one of 149 their tibiae, resulting in improper decalcification and Osmium staining. Therefore, 4/5 animals in group 1, $1506 / 7$ animals in group 2, and 7/7 animals in group 3 were included.

\section{$151 \quad 2.8$ Histomorphometry}

152 Tibiae and surrounding muscles in groups 4-6 were embedded in MMA for histomorphometric analysis.

153 Sections were cut at $30 \%$ (see Figure 2C) of the distance between tibia-fibula junctions, approximately in

154 the middle of the portion affected by surgical marrow aspiration. The sections were cut with a 4- $\mu \mathrm{m}$

155 thickness for optimal osteoblast and osteoclast visualization. In each tibia, one slide was left unstained to

156 measure dynamic parameters with fluorochrome labeling. A second slide was stained with tartrate-

157 resistant acid phosphatase (TRAP) to count osteoclasts, and a third slide was stained with $2 \%$ toluidine

158 blue to measure osteoid and osteoblasts (please read Supplementary Methods for more information on

159 staining protocol).

160 Sections were analyzed with OsteoMeasure software (OsteoMetrics, Atlanta, GA, USA). Overall, mineral 161 apposition rate (MAR), mineralizing surface (MS), bone formation rate (BFR), number of osteoblasts and 162 osteoclasts (N.Ob and N.Oc), as well as osteoid width and surface (O.Wi and OS) were measured. MAR 163 was calculated as MAR = Ir.L.Wi / $t$, where Ir.L.Wi is the interlabel width, $t$ is the time interval between 164 the first and second sets of fluorochrome injections. MS was calculated as sLS/2+dLS, where sLS is the 165 length of single label marking, and dLS is the length of double label marking. BFR was calculated as 166 MAR x BS. Parameters were analyzed as periosteal or non-periosteal, which comprised endosteal, 167 trabecular, intramedullary, and intracortical labels or cells. Non-periosteal parameters were grouped 168 together, because the endosteal perimeter was not clearly defined in many animals (see Supplementary

169 Figure S1). Therefore, conventional classification would be too dependent on personal interpretation and 170 location of the section. What appears as an intracortical cavity may be interpreted as trabecular bone a 
171 few sections away. Histomorphometric results are usually reported normalized to the bone surface BS,

172 which may or may not be labeled. In this study, histomorphometric parameters were not normalized to

173 bone surface (MS was reported, instead of MS/BS, BFR instead of BFR/BS, N.Ob instead of N.Ob/BS,

174 and N.Oc instead of N.Oc/BS), because normalizing would not capture the absolute and variable

175 formation of bone inside the medullary canal. Many bones with high bone formation activity also have

176 increased bone surface compared to bones with lower amounts of activity. Normalizing by bone surface

177 does not capture the increase in overall amount of bone formation activity.

178

179

180

181

182

\subsection{Statistical analysis}

Micro-CT data: For total bone sectional area, we compared, within each group, bone area (continuous data) along the tibia-fibula junctions (normalized field) in the right versus left tibia. To allow multiple comparisons of these data along the field, we used one-dimensional statistical parametric mapping (Spm1d [28]). This method uses random field theory to perform statistical tests on normalized sets of 1D measurements that are continuous in space or in time, and corrects for the multiple comparison problem [29]. We used two-tailed two-sample t-tests in Spm1d, to test the null hypothesis that mean bone area in the left and right tibiae are equal. We reported the location of the clusters where the null-hypothesis was rejected, as well as the associated p-value. We also compared, within each group, intramedullary bone volume (groups 1-6) and adipose tissue volume (groups 1-3) in the right versus left tibiae. The difference (right - left) was not always normally distributed according to Kolmogorov-Smirnov tests, therefore nonparametric Wilcoxon sign-rank tests were used, with the null hypothesis that left and right distributions were the same within each group.

Histomorphometry: Within a group, we compared histomorphometric parameters in the right versus left tibiae using Wilcoxon signed-rank tests, with the hypothesis that distributions were equal. This determined the effect of aspiration/loading relative to the contralateral leg. Then, because aspiration promoted some systemic changes in bone formation, we compared histomorphometric parameters across groups. We used Kruskal-Wallis tests to compare left tibiae, and then right tibiae, across the 3 groups, 
196 with the null hypothesis that distributions are equal across groups. When Kruskal-Wallis tests indicated

197 that distributions were not equal across groups, we performed post-hoc analysis to determine which group 198 was different from the others. Post-hoc analysis was performed with Wilcoxon rank-sum tests, using the 199 Bonferroni correction for multiple comparisons, with the null hypothesis that distributions are equal. 


\section{Results}

\subsection{Effects of marrow aspiration on bone and marrow adipose tissue}

2 weeks after aspiration, bone cross-sectional area was higher in the right aspirated tibiae around 12-13\% of the normalized location on tibia, compared to the left contralateral tibiae (Figure 4, group 2, p<0.01). This increase in bone amount was in part caused by formation of bone in the medullary canal: after 2 weeks, the volume of intramedullary bone was significantly higher in the right than in the left tibiae (Figure 5, $\mathrm{p}<0.05$ ). 1, 4, and 6 weeks after aspiration, bone cross-sectional area was not different in the left and right tibiae (Figure 4, groups 1, 3, and 4). 3 mice out of 22 that had aspiration presented elevated levels of intramedullary bone in the contralateral tibiae as well (Figure 5, more than $0.25 \mathrm{~mm}^{3}$, which is more than ten times the mean intramedullary bone volume in the left tibia of mice that did not have marrow aspiration, groups 3, 4, and 6). Supplementary Figure S2 shows examples of intramedullary bone distribution after marrow aspiration, in the left and right tibiae.

2 weeks and 4 weeks after marrow aspiration, the amount of adipose tissue increased in the right tibiae, compared to left (Figure 6, groups 2 and 3, $\mathrm{p}<0.05,140 \%$ increase in the right compared to left tibia at 2 weeks, 39\% increase at 4 weeks). Supplementary Figure S3 shows examples of marrow adipose tissue distribution after marrow aspiration, in the left and right tibiae.

\subsection{Combined effects of aspiration and loading}

Loading the right tibiae increased bone cross-sectional area at $47 \%-49 \%$ between tibia-fibula junctions, compared to the left contralateral tibiae (Figure 4, group 5). This corresponds to the region where strains are highest and where loading-induced formation is usually observed (about $37 \%$ of the total tibial length, [30-32]). Right tibiae that had aspiration + loading had higher bone cross-sectional area at $1 \%$ between the tibia-fibula junctions, compared to left tibiae (Figure 4, group 6). This increase was located at the very proximal end, where a lot of intramedullary bone was present 6 weeks after marrow aspiration. 
224 Intramedullary bone volume was no different between the left and right tibiae within groups 4, 5, and 6 225 (Figure 5).

\section{$226 \quad 3.2$ Histomorphometry}

227 3.2.1 Effects of aspiration and/or loading in the right tibia, compared to left (contralateral)

228 Aspiration alone increased non-periosteal bone formation in the right tibia, compared to the left (Figure

229 7). Non-periosteal mineral apposition rate and bone formation rate were higher in the right tibia,

230 compared to the left (Table 1A, group 4). No difference was observed in cell numbers (osteoblasts and

231 osteoclasts) or in osteoid parameters. Supplementary figure S1 shows sections of a mouse with very high

232 amounts of bone formation in the medullary canal and high intracortical remodeling, and illustrates why it

233 is difficult in this experiment to discriminate non-periosteal parameters (endosteal / intracortical /

234 trabecular / intramedullary). This mouse in particular had elevated amounts of intramedullary bone (navy

235 blue six-pointed star on figure 5, group 4).

236 Loading alone overall increased bone formation in the right tibia, compared to the left (Figure 8).

237 Periosteal mineral apposition rate, bone formation rate, and osteoid surface, as well as non-periosteal

238 bone formation rate and osteoid surface, were higher in the right tibia compared to the left (Tables $1 \mathrm{~A}$ and

$2392 \mathrm{~A}$, group 5). No difference was observed in cell numbers (osteoblasts and osteoclasts).

240 When aspiration and loading were combined, the response was a mix of what was seen in aspiration and

241 in loading, as both periosteal and non-periosteal bone formation were increased in the right tibia,

242 compared to the left (Figure 9). Periosteal mineralizing surface, mineral apposition rate, bone formation

243 rate, osteoid width, osteoid surface, as well as non-periosteal mineral apposition rate were higher in the

244 right tibia, compared to the left (Tables 1A and 2A, group 6). No difference was observed in cell numbers

245 (osteoblasts and osteoclasts).

246 3.2.2 Mice that had marrow aspiration in the right tibia had lower periosteal formation in the left tibia 
247 We compared left (contralateral) tibiae across groups. Mice that had marrow aspiration (groups 4 and 6)

248 had lower periosteal mineralizing surface, mineral apposition rate, and bone formation rate in the left

249 tibia, compared to mice that had loading alone (group 5) (Table 1B).

\subsubsection{Following marrow aspiration, the periosteal response to loading was decreased}

251 We compared all right tibiae (aspiration and/or loading) across groups. Mice that had loading (groups 5 252 and 6) had higher periosteal and non-periosteal bone formation in the right tibia, compared to mice that 253 had aspiration alone (group 4). Similarly, mice that had loading had less periosteal osteoclasts, compared 254 to mice that had aspiration alone. For instance, periosteal and non-periosteal mineral apposition rate in the 255 right tibia were higher in groups $4 \underline{5}$ and 6, compared to group 4 (Table 1B). Loading-induced periosteal 256 bone formation was even higher in mice that had loading alone (group 5), compared to mice that had 257 marrow aspiration + loading (group 6). For instance, periosteal mineralizing surface and bone formation 258 rate in the right tibia were higher in group 5, compared to group 6 (Table 1B).

\section{Discussion}

To our knowledge, this is the first study to examine marrow aspiration in old mice (20-23 months of age).

262 These data indicate bone formation in the medullary canal 2 weeks following aspiration, indicating aged

263 bone has the cellular machinery to make bone. Interestingly, the increase in bone formation was

264 accompanied by an increase in marrow adiposity. While the increase in adipocytes following aspiration

265 has been reported based on histological sections in young mice [33] and in 1-month old immuno-

266 compromised rats (but no increase was observed in 3- and 10-month-old animals) [21], no study has

267 examined the effects of aspiration on marrow adipose tissue in old rodents. In particular, no study has 268 quantified the total volume of marrow adipose tissue following aspiration in both tibiae. Given the 269 variability in volume and distribution of regulated marrow adipose tissue, results from histological 270 sections might depend greatly on the location of the section, while 3D osmium imaging captures marrow 
271 adipose tissue in its totality. Using osmium staining, and despite high variability in marrow distribution

272 and low sample size, the present study found that marrow adipose tissue increased following aspiration.

273 Cell fate is altered with age, and common progenitors tend to differentiate into adipocytes rather than

274 osteoblasts [9-11]. The increase in marrow adiposity following marrow aspiration might be due to the

275 recruitment of stem cells, part of which differentiated into adipocytes. Future studies could examine

276 senescence markers to provide valuable information on bone environment after marrow aspiration.

277 Interestingly, marrow aspiration reduced periosteal bone formation in the contralateral tibiae of mice that

278 had aspiration, compared to contralateral tibiae of mice that did not have aspiration. This decrease in

279 periosteal formation was captured during the last 2 weeks of the experiment, starting 4 weeks after

280 aspiration, and suggests that bone anabolism is reduced in a systemic manner. Further studies are needed

281 to investigate this mechanism. Measuring serum bone turnover markers for instance would provide

282 insight on the systemic response in this study.

283 Tibiae that had aspiration + loading had lower periosteal formation compared to tibiae that had loading

284 alone. The same load magnitude $(9 \mathrm{~N})$ was applied to both groups, because the transient formation of

285 bone in the medullary canal close to the neutral axis in bending (induced by tibial loading) likely did not

286 alter much the mechanical cues experienced in the cortex, especially close to the periosteal surface.

287 Additionally, even mice that did not present intramedullary bone following aspiration had lower levels of

288 periosteal bone formation, compared to mice that did not have aspiration. Marrow aspiration might have

289 reduced baseline periosteal formation in the aspirated tibiae (like it did in the contralateral tibiae), and the

290 mechano-adaptive response to loading was further reduced. Moreover, initiating loading sessions earlier

291 after marrow aspiration might yield a different outcome, for instance 2 weeks after aspiration, when the

292 aspirated tibia still had more bone than the contralateral.

293 Interestingly, the decrease in periosteal mechano-adaptation coincided with the increase in bone marrow

294 adiposity following marrow aspiration. High marrow adiposity has been linked with skeletal fragility [34-

295 36], and bone marrow adipose tissue can modulate osteoblast and osteoclast differentiation [37-43]. 
296 Communication across the cortex between the endosteal and periosteal surfaces might mediate the

297 decrease in periosteal mechano-adaptation, but further studies would be required to elucidate this

298 mechanism.

299 Histomorphometric sections showed varying levels of intracortical remodeling in all groups (with or

300 without aspiration). Intracortical remodeling in old mice has been evidenced recently [44]. The amount of

301 intracortical remodeling was however variable across animals and even within the same animal, and we

302 found no correlation to periosteal bone formation (analysis presented in Supplementary material).

303

304

305

306

307

308

309

310

311

312

313

314

315

316

317

318 319

The lack of a group of baseline controls (age-matched, non-loaded, non-aspirated) is a limitation in this study. However, the mechano-adaptive response to in vivo tibial loading for cortical and trabecular bone is confined to the loaded leg [45], and most studies employing tibial loading use the contralateral leg as internal control [1-5]. Therefore, contralateral limbs in group 4 $\underline{5}$ (no loading, not affected by marrow aspiration) provide baseline information for this experiment. We decided to reduce our sample size (supporting the 3Rs in animal research) by using the contralateral leg as a control rather than having a separate control group as it provides the same information. This study can help to inform sample size in future studies.

Marrow aspiration in the proximal site of the tibia might have been incomplete in these mice, and the osteogenic response observed could have been a response to marrow injury by the needle and turbulent motion of saline, rather than the actual removal of marrow by aspiration. Marrow aspiration is always accompanied by injury, and we do not know if injury alone would produce the same results. In young mice (15 weeks of age, BMP2 BAC transgenic males), reaming of the tibial marrow with needles was sufficient to induce an osteogenic response (increased BMP2 expression and CD73 positive cells within 2 weeks following injury) [46]. However, whether it is caused by injury or aspiration and regeneration, the procedure results in an osteogenic response along with increased marrow adiposity. 


\section{5. Conclusion}

321 In old mice, there was transiently more bone formed in the medullary canal of the aspirated tibiae

322 compared to contralateral tibiae, while marrow adiposity was increased. After marrow aspiration, the

323 periosteal mechano-adaptive response to tibial loading was decreased as evidenced by dynamic

324 histomorphometry. In the contralateral tibiae, periosteal bone formation was reduced. These intriguing

325 results indicate that old bone is capable of forming transiently in the medullary canal in response to

326 marrow aspiration. However, periosteal formation and mechano-adaptation in response to loading are

327 reduced. This might have implications for bone health in elderly patients with marrow injury. 
1. De Souza RL, Matsuura M, Eckstein F, Rawlinson SCF, Lanyon LE, Pitsillides AA. Noninvasive axial loading of mouse tibiae increases cortical bone formation and modifies trabecular organization: A new model to study cortical and cancellous compartments in a single loaded element. Bone. 2005;37: 810-818. doi:10.1016/j.bone.2005.07.022

2. Fritton J, Myers E, Wright T, Vandermeulen M. Loading induces site-specific increases in mineral content assessed by microcomputed tomography of the mouse tibia. Bone. 2005;36: 1030-1038. doi:10.1016/j.bone.2005.02.013

3. Holguin N, Brodt MD, Sanchez ME, Silva MJ. Aging diminishes lamellar and woven bone formation induced by tibial compression in adult C57BL/6. Bone. 2014;65: 83-91. doi:10.1016/j.bone.2014.05.006

4. Razi H, Birkhold AI, Weinkamer R, Duda GN, Willie BM, Checa S. Aging Leads to a Dysregulation in Mechanically Driven Bone Formation and Resorption. Journal of Bone and Mineral Research. 2015;30: 1864-1873. doi:10.1002/jbmr.2528

5. Meakin LB, Galea GL, Sugiyama T, Lanyon LE, Price JS. Age-Related Impairment of Bones' Adaptive Response to Loading in Mice Is Associated With Sex-Related Deficiencies in Osteoblasts but No Change in Osteocytes. Journal of Bone and Mineral Research. 2014;29: 1859-1871. doi:10.1002/jbmr.2222

6. Perkins SL, Gibbons R, Kling S, Kahn AJ. Age-related bone loss in mice is associated with an increased osteoclast progenitor pool. Bone. 1994;15: 65-72. doi:10.1016/87563282(94)90893-1

7. Cao JJ, Wronski TJ, Iwaniec U, Phleger L, Kurimoto P, Boudignon B, et al. Aging Increases Stromal/Osteoblastic Cell-Induced Osteoclastogenesis and Alters the Osteoclast Precursor Pool in the Mouse. Journal of Bone and Mineral Research. 2005;20: 1659-1668. doi:10.1359/JBMR.050503

8. Koshihara Y, Suematsu A, Feng D, Okawara R, Ishibashi H, Yamamoto S. Osteoclastogenic potential of bone marrow cells increases with age in elderly women with fracture. Mechanisms of Ageing and Development. 2002;123: 1321-1331. doi:10.1016/S0047-6374(02)00071-4

9. Meunier P, Aaron J, Edouard C, Vignon G. Osteoporosis and the replacement of cell populations of the marrow by adipose tissue. A quantitative study of 84 iliac bone biopsies. Clin Orthop Relat Res. 1971;80: 147-154.

10. Moerman EJ, Teng K, Lipschitz DA, Lecka-Czernik B. Aging activates adipogenic and suppresses osteogenic programs in mesenchymal marrow stroma/stem cells: the role of PPAR-gamma2 transcription factor and TGF-beta/BMP signaling pathways. Aging Cell. 2004;3: 379-389. doi:10.1111/j.1474-9728.2004.00127.x

11. Singh L, Brennan TA, Russell E, Kim J-H, Chen Q, Brad Johnson F, et al. Aging alters bone-fat reciprocity by shifting in vivo mesenchymal precursor cell fate towards an adipogenic lineage. Bone. 2016;85: 29-36. doi:10.1016/j.bone.2016.01.014 
12. Kahn A, Gibbons R, Perkins S, Gazit D. Age-related bone loss. A hypothesis and initial assessment in mice. Clin Orthop Relat Res. 1995; 69-75.

13. Yang Y-M, Li P, Cui D-C, Dang R-J, Zhang L, Wen N, et al. Effect of aged bone marrow microenvironment on mesenchymal stem cell migration. AGE. 2015;37. doi:10.1007/s11357-014-9743-z

14. Nishida S, Endo N, Yamagiwa H, Tanizawa T, Takahashi HE. Number of osteoprogenitor cells in human bone marrow markedly decreases after skeletal maturation. J Bone Miner Metab. 1999;17: 171-177.

15. Muschler GF, Nitto H, Boehm CA, Easley KA. Age- and gender-related changes in the cellularity of human bone marrow and the prevalence of osteoblastic progenitors. J Orthop Res. 2001;19: 117-125. doi:10.1016/S0736-0266(00)00010-3

16. Shimizu T, Mehdi R, Yoshimura Y, Yoshikawa H, Nomura S, Miyazono K, et al. Sequential expression of bone morphogenetic protein, tumor necrosis factor, and their receptors in bone-forming reaction after mouse femoral marrow ablation. Bone. 1998;23: 127-133. doi:10.1016/S8756-3282(98)00086-6

17. Bab IA. Postablation bone marrow regeneration: an in vivo model to study differential regulation of bone formation and resorption. Bone. 1995;17: 437S-441S.

18. Yan J, Sun W, Zhang J, Goltzman D, Miao D. Bone Marrow Ablation Demonstrates That Excess Endogenous Parathyroid Hormone Plays Distinct Roles in Trabecular and Cortical Bone. The American Journal of Pathology. 2012;181: 234-244. doi:10.1016/j.ajpath.2012.03.038

19. Bab I, Gazit D, Massarawa A, Sela J. Removal of tibial marrow induces increased formation of bone and cartilage in rat mandibular condyle. Calcif Tissue Int. 1985;37: 551555.

20. Liang CT, Barnes J, Seedor JG, Quartuccio HA, Bolander M, Jeffrey JJ, et al. Impaired bone activity in aged rats: Alterations at the cellular and molecular levels. Bone. 1992;13: 435-441. doi:10.1016/8756-3282(92)90087-D

21. Fisher M, Hyzy S, Guldberg RE, Schwartz Z, Boyan BD. Regeneration of bone marrow after tibial ablation in immunocompromised rats is age dependent. Bone. 2010;46: 396401. doi:10.1016/j.bone.2009.09.029

22. Zhang Q, Miller C, Bible J, Li J, Xu X, Mehta N, et al. Additive Effects of Mechanical Marrow Ablation and PTH Treatment on de Novo Bone Formation in Mature Adult Rats. Cells. 2012;1: 1168-1181. doi:10.3390/cells1041168

23. Tsuji K, Komori T, Noda M. Aged Mice Require Full Transcription Factor, Runx2/Cbfa1, Gene Dosage for Cancellous Bone Regeneration After Bone Marrow Ablation. Journal of Bone and Mineral Research. 2004;19: 1481-1489. doi:10.1359/JBMR.040601 
24. Piet J, Hu D, Meslier Q, Baron R, Shefelbine SJ. Increased Cellular Presence After Sciatic Neurectomy Improves the Bone Mechano-adaptive Response in Aged Mice. Calcif Tissue Int. 2019 [cited 30 Jul 2019]. doi:10.1007/s00223-019-00572-7

25. Doube M, Kłosowski MM, Arganda-Carreras I, Cordelières FP, Dougherty RP, Jackson JS, et al. BoneJ: Free and extensible bone image analysis in ImageJ. Bone. 2010;47: 10761079. doi:10.1016/j.bone.2010.08.023

26. Scheller EL, Troiano N, Vanhoutan JN, Bouxsein MA, Fretz JA, Xi Y, et al. Use of osmium tetroxide staining with microcomputerized tomography to visualize and quantify bone marrow adipose tissue in vivo. Meth Enzymol. 2014;537: 123-139. doi:10.1016/B978-0-12-411619-1.00007-0

27. Scheller EL, Doucette CR, Learman BS, Cawthorn WP, Khandaker S, Schell B, et al. Region-specific variation in the properties of skeletal adipocytes reveals regulated and constitutive marrow adipose tissues. Nat Commun. 2015;6: 7808. doi: $10.1038 /$ ncomms 8808

28. Pataky TC. One-dimensional statistical parametric mapping in Python. Computer Methods in Biomechanics and Biomedical Engineering. 2012;15: 295-301. doi:10.1080/10255842.2010.527837

29. Pataky TC. Generalized n-dimensional biomechanical field analysis using statistical parametric mapping. Journal of Biomechanics. 2010;43: 1976-1982. doi:10.1016/j.jbiomech.2010.03.008

30. Carriero A, Pereira AF, Wilson AJ, Castagno S, Javaheri B, Pitsillides AA, et al. Spatial relationship between bone formation and mechanical stimulus within cortical bone: Combining 3D fluorochrome mapping and poroelastic finite element modelling. Bone Rep. 2018;8: 72-80. doi:10.1016/j.bonr.2018.02.003

31. Sugiyama T, Saxon LK, Zaman G, Moustafa A, Sunters A, Price JS, et al. Mechanical loading enhances the anabolic effects of intermittent parathyroid hormone (1-34) on trabecular and cortical bone in mice. Bone. 2008;43: 238-248. doi:10.1016/j.bone.2008.04.012

32. Piet J, Hu D, Baron R, Shefelbine SJ. Bone adaptation compensates resorption when sciatic neurectomy is followed by low magnitude induced loading. Bone. 2019;120: 487-494. doi:10.1016/j.bone.2018.12.017

33. Bragdon B, Lybrand K, Gerstenfeld L. Overview of biological mechanisms and applications of three murine models of bone repair: closed fracture with intramedullary fixation, distraction osteogenesis, and marrow ablation by reaming. Curr Protoc Mouse Biol. 2015;5: 21-34. doi:10.1002/9780470942390.mo140166

34. Shen W, Scherzer R, Gantz M, Chen J, Punyanitya M, Lewis CE, et al. Relationship between MRI-measured bone marrow adipose tissue and hip and spine bone mineral 
density in African-American and Caucasian participants: the CARDIA study. J Clin Endocrinol Metab. 2012;97: 1337-1346. doi:10.1210/jc.2011-2605

35. Justesen J, Stenderup K, Ebbesen EN, Mosekilde L, Steiniche T, Kassem M. Adipocyte tissue volume in bone marrow is increased with aging and in patients with osteoporosis. Biogerontology. 2001;2: 165-171.

36. Bredella MA, Fazeli PK, Daley SM, Miller KK, Rosen CJ, Klibanski A, et al. Marrow fat composition in anorexia nervosa. Bone. 2014;66: 199-204. doi:10.1016/j.bone.2014.06.014

37. Xu J-C, Wu G-H, Zhou L-L, Yang X-J, Liu J-T. Leptin improves osteoblast differentiation of human bone marrow stroma stem cells. Eur Rev Med Pharmacol Sci. 2016;20: 35073513.

38. Luo X-H, Guo L-J, Yuan L-Q, Xie H, Zhou H-D, Wu X-P, et al. Adiponectin stimulates human osteoblasts proliferation and differentiation via the MAPK signaling pathway. Exp Cell Res. 2005;309: 99-109. doi:10.1016/j.yexcr.2005.05.021

39. Wang D, Haile A, Jones LC. Dexamethasone-induced lipolysis increases the adverse effect of adipocytes on osteoblasts using cells derived from human mesenchymal stem cells. Bone. 2013;53: 520-530. doi:10.1016/j.bone.2013.01.009

40. Muruganandan S, Roman AA, Sinal CJ. Role of chemerin/CMKLR1 signaling in adipogenesis and osteoblastogenesis of bone marrow stem cells. J Bone Miner Res. 2010;25: 222-234. doi:10.1359/jbmr.091106

41. Oh S-R, Sul O-J, Kim Y-Y, Kim H-J, Yu R, Suh J-H, et al. Saturated fatty acids enhance osteoclast survival. J Lipid Res. 2010;51: 892-899. doi:10.1194/jlr.M800626

42. Goto H, Hozumi A, Osaki M, Fukushima T, Sakamoto K, Yonekura A, et al. Primary human bone marrow adipocytes support TNF- $\alpha$-induced osteoclast differentiation and function through RANKL expression. Cytokine. 2011;56: 662-668.

doi:10.1016/j.cyto.2011.09.005

43. Hozumi A, Osaki M, Goto H, Sakamoto K, Inokuchi S, Shindo H. Bone marrow adipocytes support dexamethasone-induced osteoclast differentiation. Biochem Biophys Res Commun. 2009;382: 780-784. doi:10.1016/j.bbrc.2009.03.111

44. Piemontese M, Almeida M, Robling AG, Kim H-N, Xiong J, Thostenson JD, et al. Old age causes de novo intracortical bone remodeling and porosity in mice. JCI Insight. 2017;2. doi:10.1172/jci.insight.93771

45. Sugiyama T, Price JS, Lanyon LE. Functional adaptation to mechanical loading in both cortical and cancellous bone is controlled locally and is confined to the loaded bones. Bone. 2010;46: 314-321. doi:10.1016/j.bone.2009.08.054 
474 46. Marsell R, Steen B, Bais MV, Mortlock DP, Einhorn TA, Gerstenfeld LC. Skeletal trauma 475 generates systemic BMP2 activation that is temporally related to the mobilization of CD73+ 476 cells. J Orthop Res. 2014;32: 17-23. doi:10.1002/jor.22487

477

478 
A) Marrow aspiration

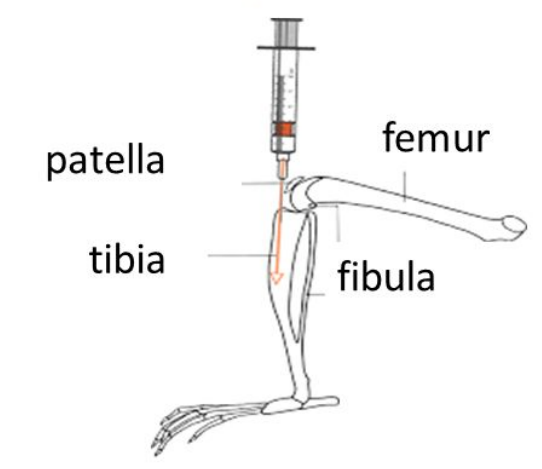

C) Sample analysis
B) Experimental timeline

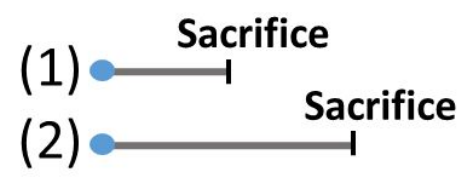

(3)

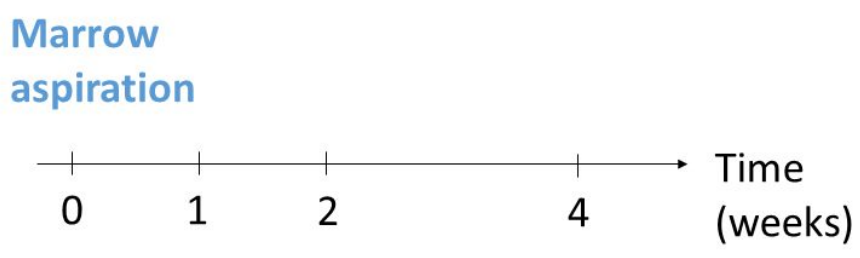

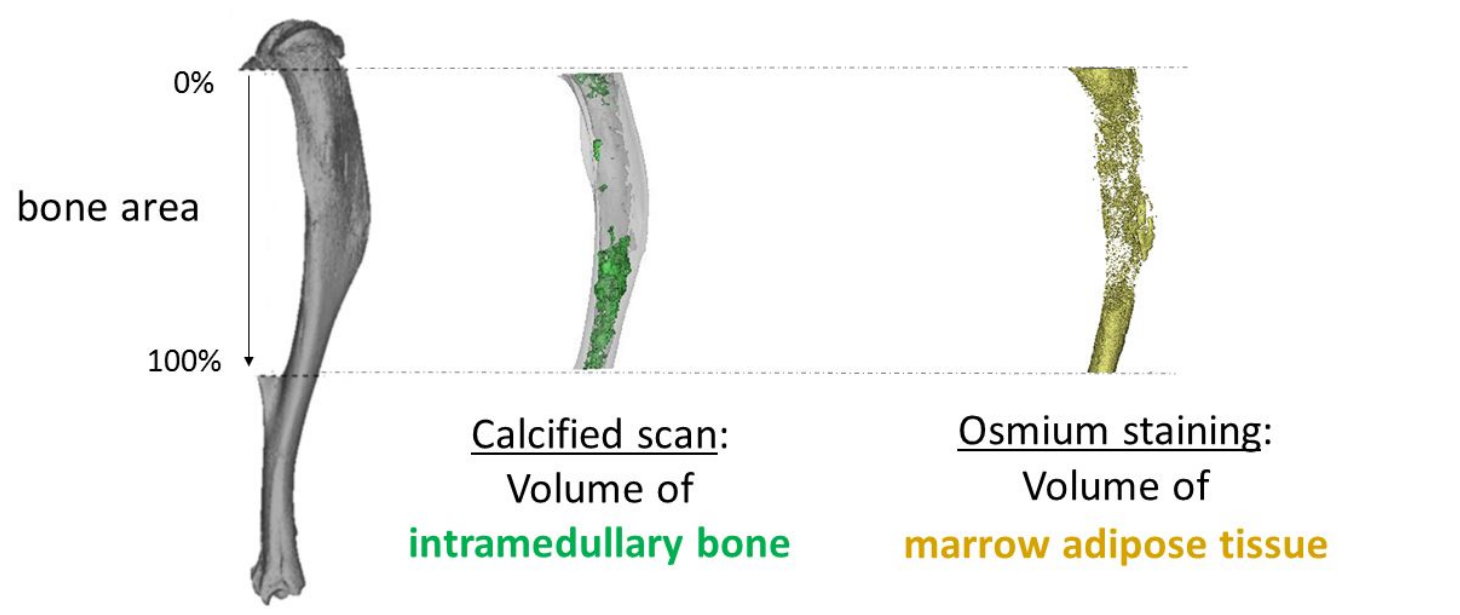

Figure 1: Experimental groups 1-3. (A) Marrow aspiration was performed in the right tibia with a saline-filled syringe. Left tibia was kept intact. (B) Mice in groups 1-3 were sacrificed 1, 2, and 4 weeks after aspiration. (C) Bone area was analyzed along the tibia, between tibia-fibula junctions. Total volume of intramedullary bone and marrow adipose tissue between tibia-fibula junctions was measured. 


\section{$\begin{array}{lll}\text { A) Tibial loading } & \text { B) Experimental timeline }\end{array}$}

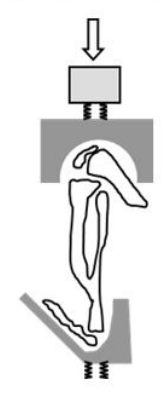

(4)

(5)

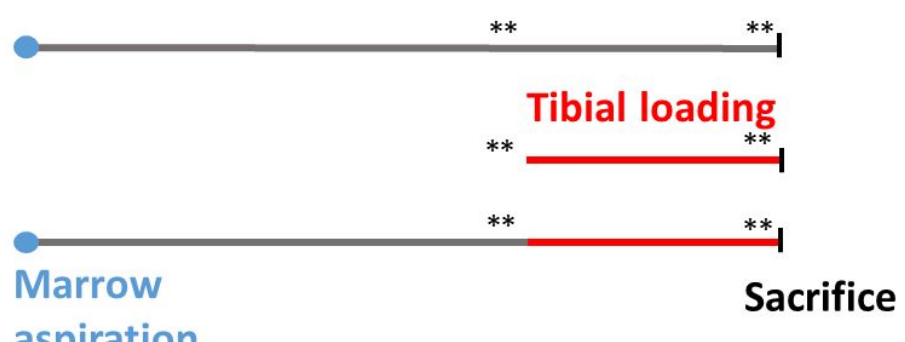

aspiration

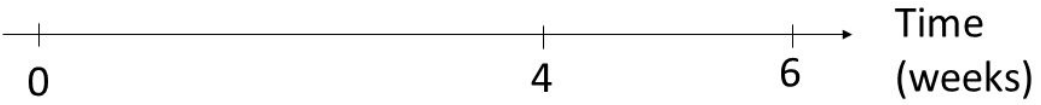

\section{C) Sample analysis}

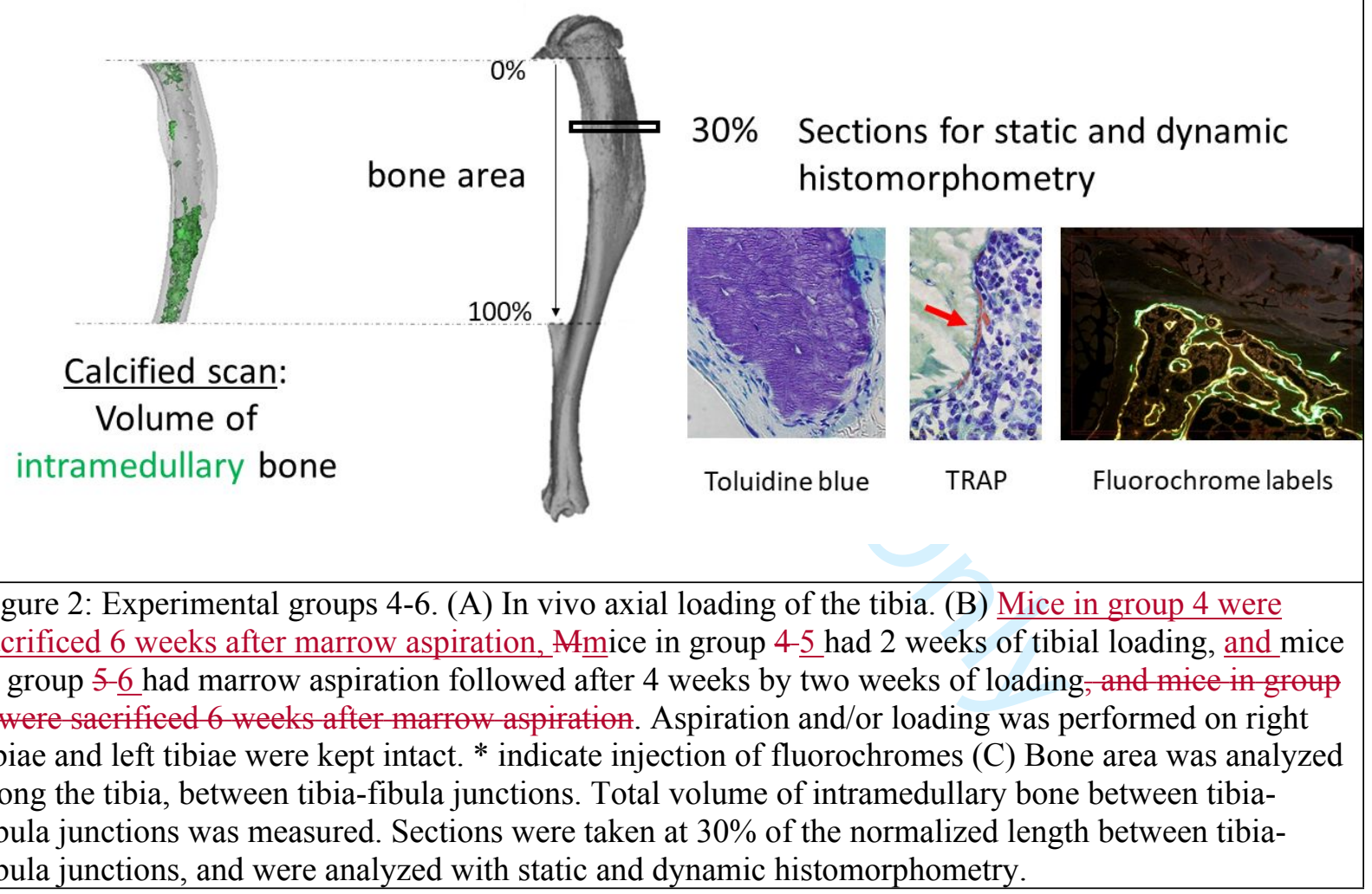

fibula junctions, and were analyzed with static and dynamic histomorphometry. 


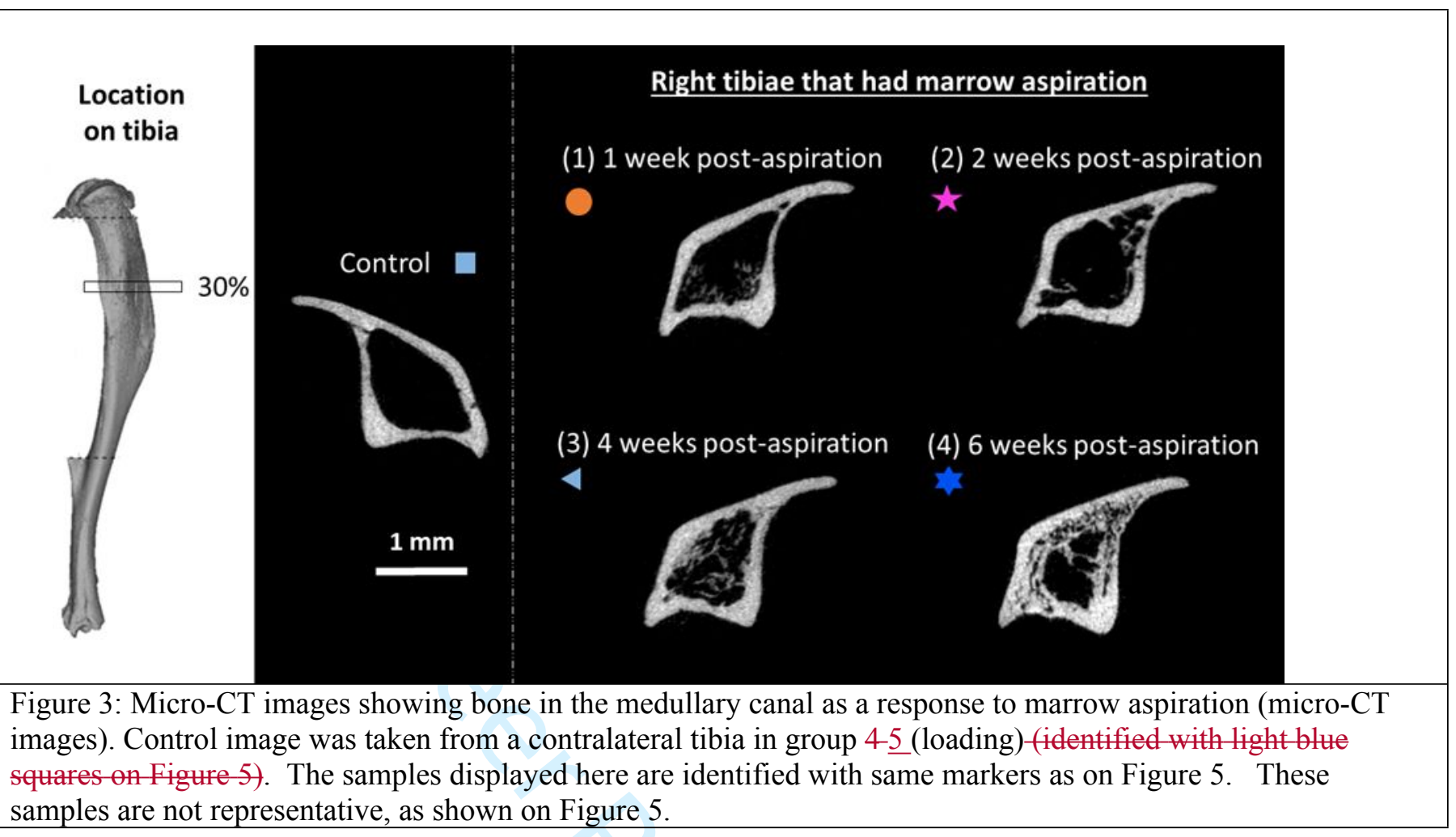

487 

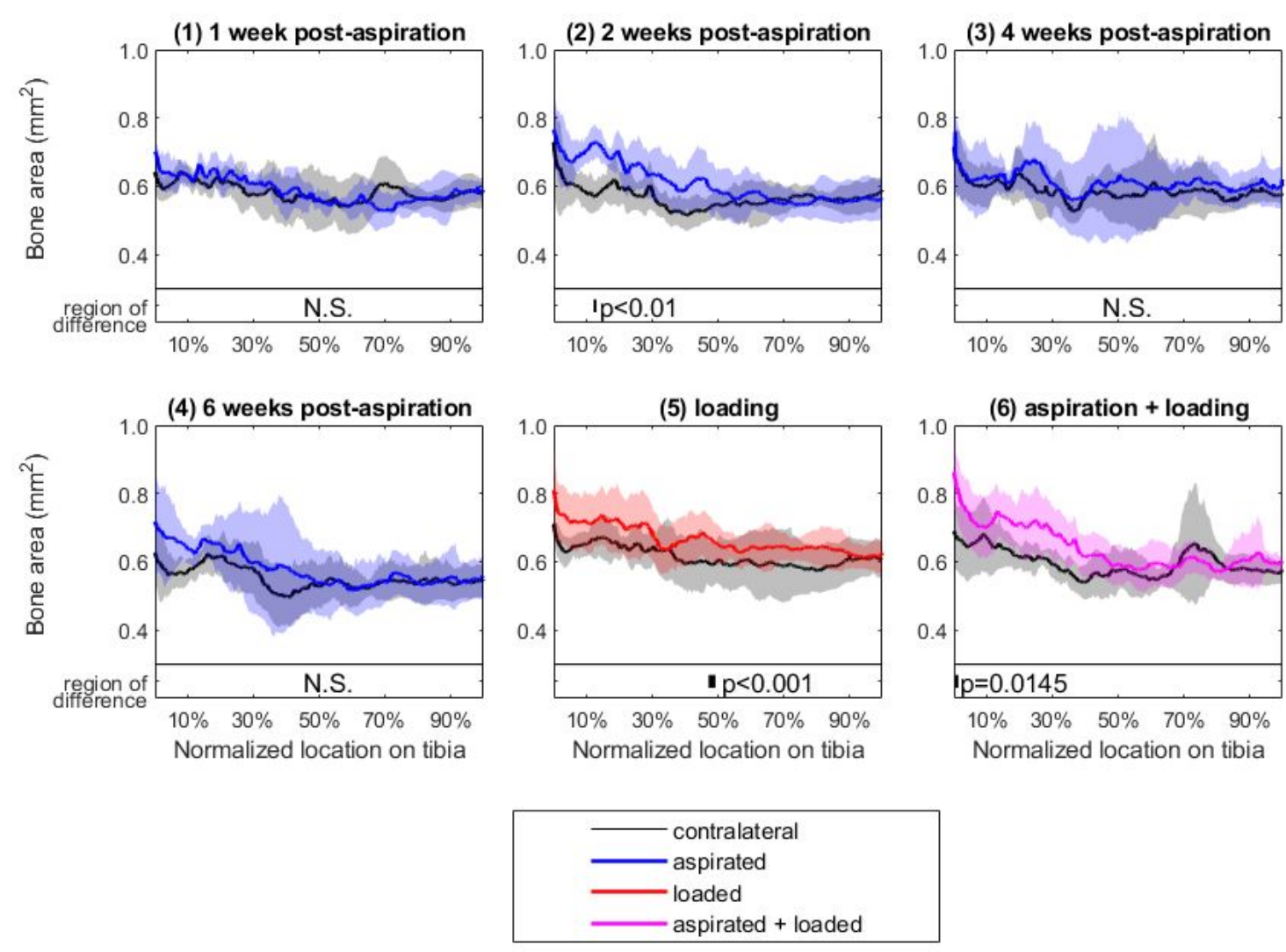

Figure 4: Bone area along the tibia, between tibia-fibula junctions ( $0 \%$ : proximal junction, $100 \%$ distal junction). Solid line: mean; shaded area: standard deviation.

Bone area in right (aspiration and/or loading) and left (contralateral, in black) tibiae were compared using paired t-tests in Spm1d, with the null hypothesis that means were equal.

'N.S.' = non-significant. Bars and p-values indicate the region where left and right tibiae have different bone area.

All animals are included. 

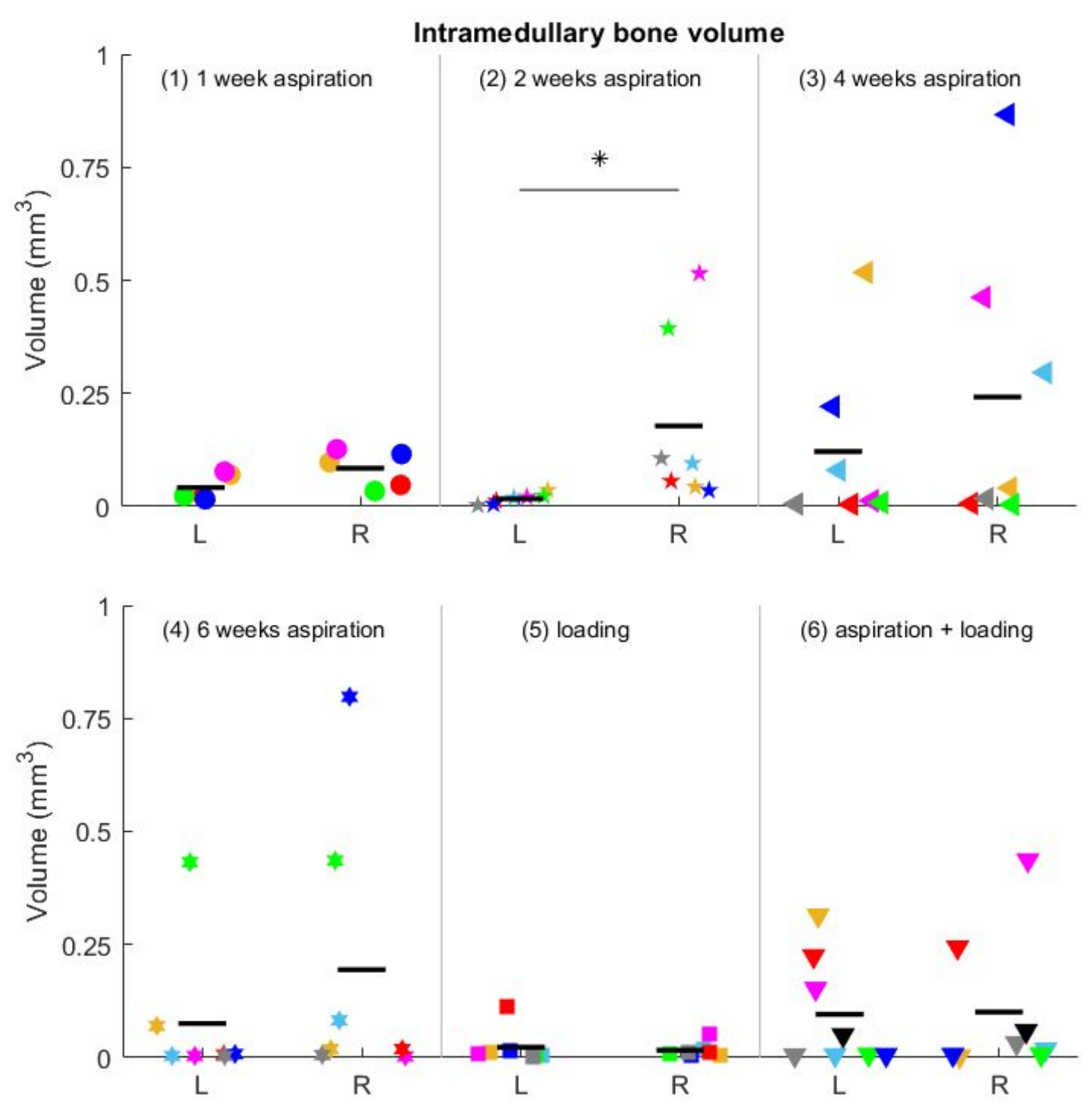

Figure 5: Amount of intramedullary bone in all groups, in the left (L, contralateral controls) and right $(\mathrm{R}$, aspiration and/or loading) tibiae. Horizontal bars represent the mean of each distribution. Each mouse is represented with a different marker type and color. Intramedullary bone volume within each group was tested with a Wilcoxon signed-rank tests, with the null hypothesis that distributions are equal. $* \mathrm{p}<0.05$

All animals are included. 


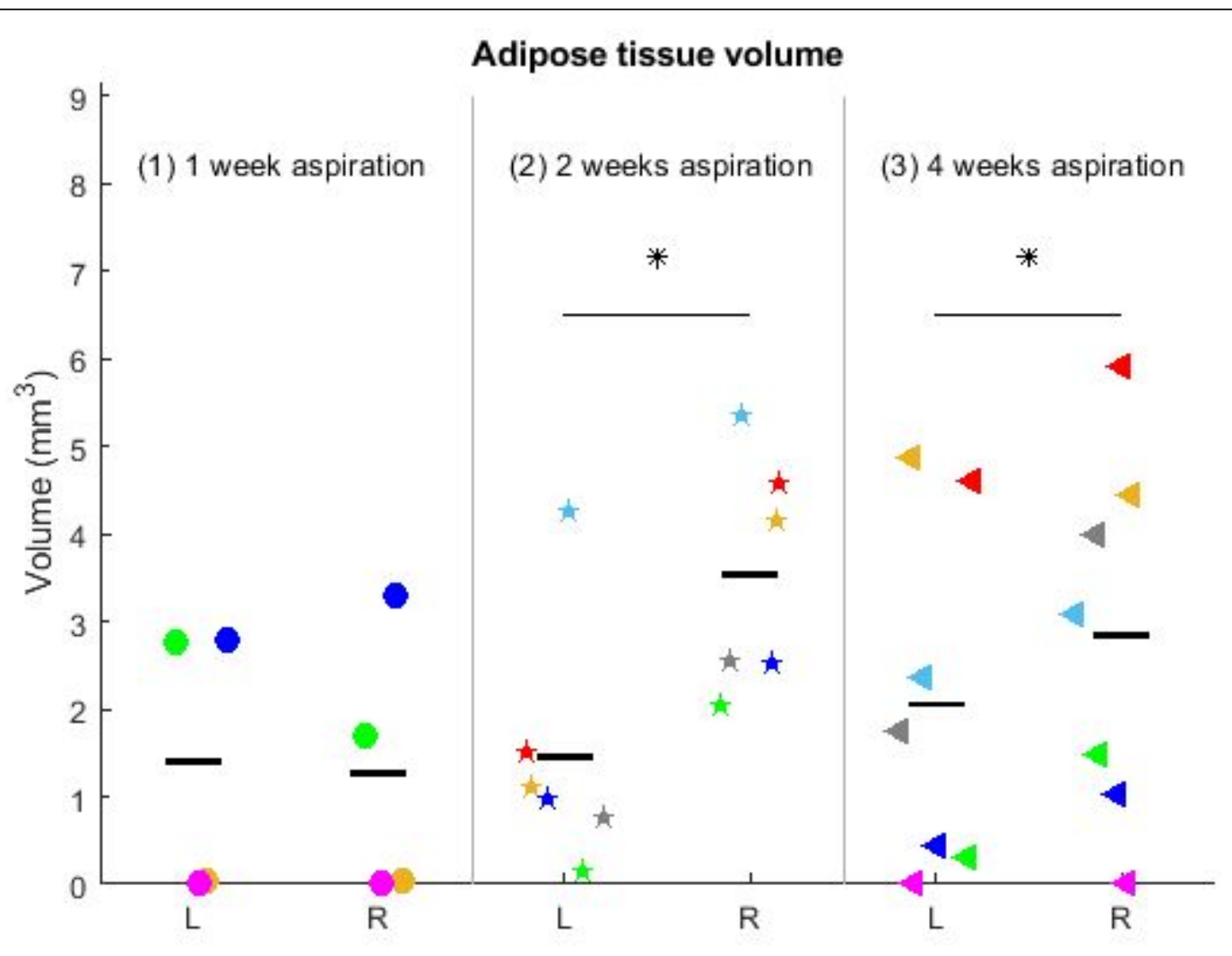

Figure 6: Amount of adipose volume (obtained by osmium staining) in the left (L, contralateral controls) and right ( $R$, aspiration) tibiae, for groups 1-3. Horizontal bars represent the mean of each distribution. Each mouse is represented with the same marker type and color as in Figure 5. Adipose tissue volume within each group was tested with a Wilcoxon signed-rank tests, with the null hypothesis that distributions are equal. ${ }^{*} \mathrm{p}<0.05$ 


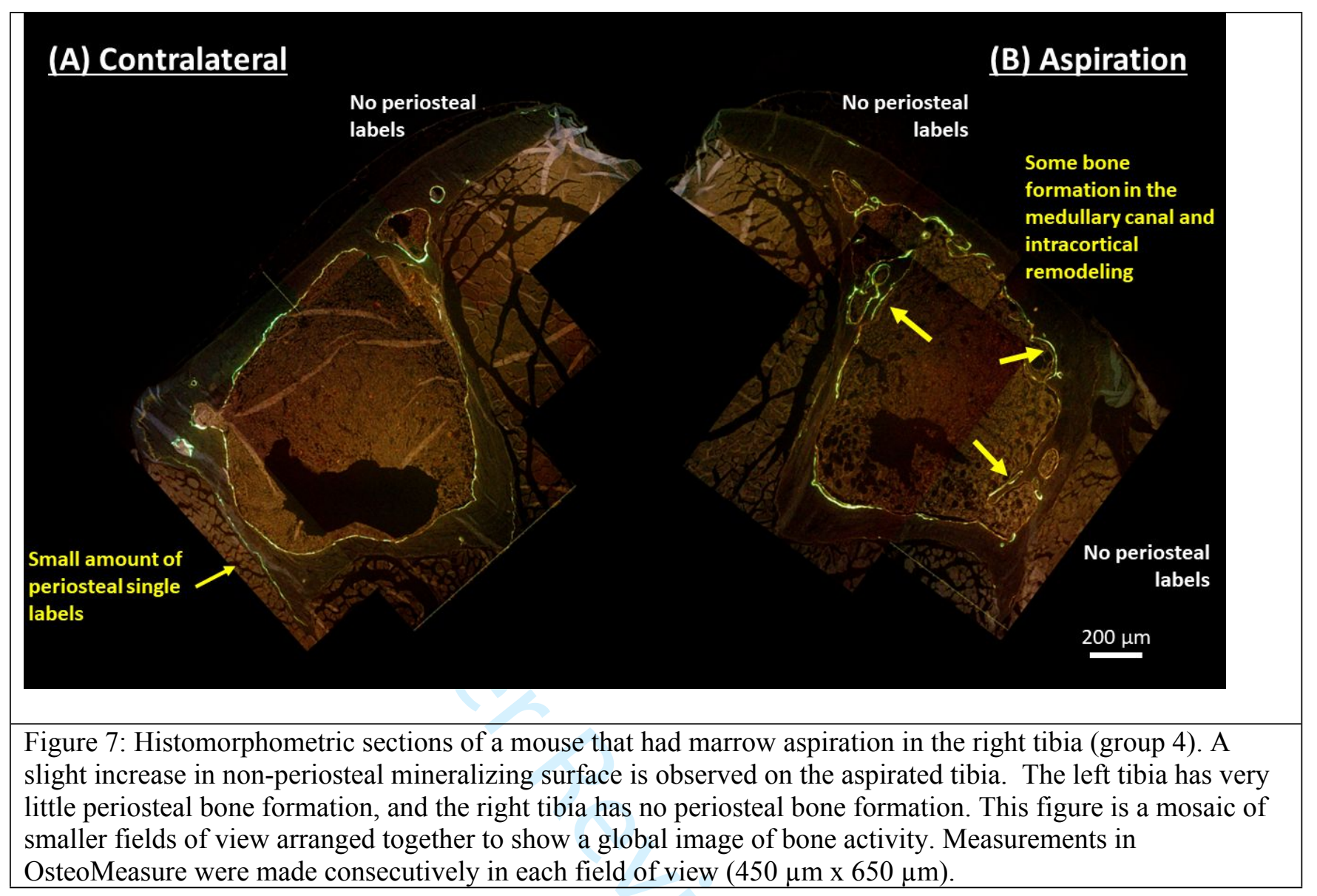




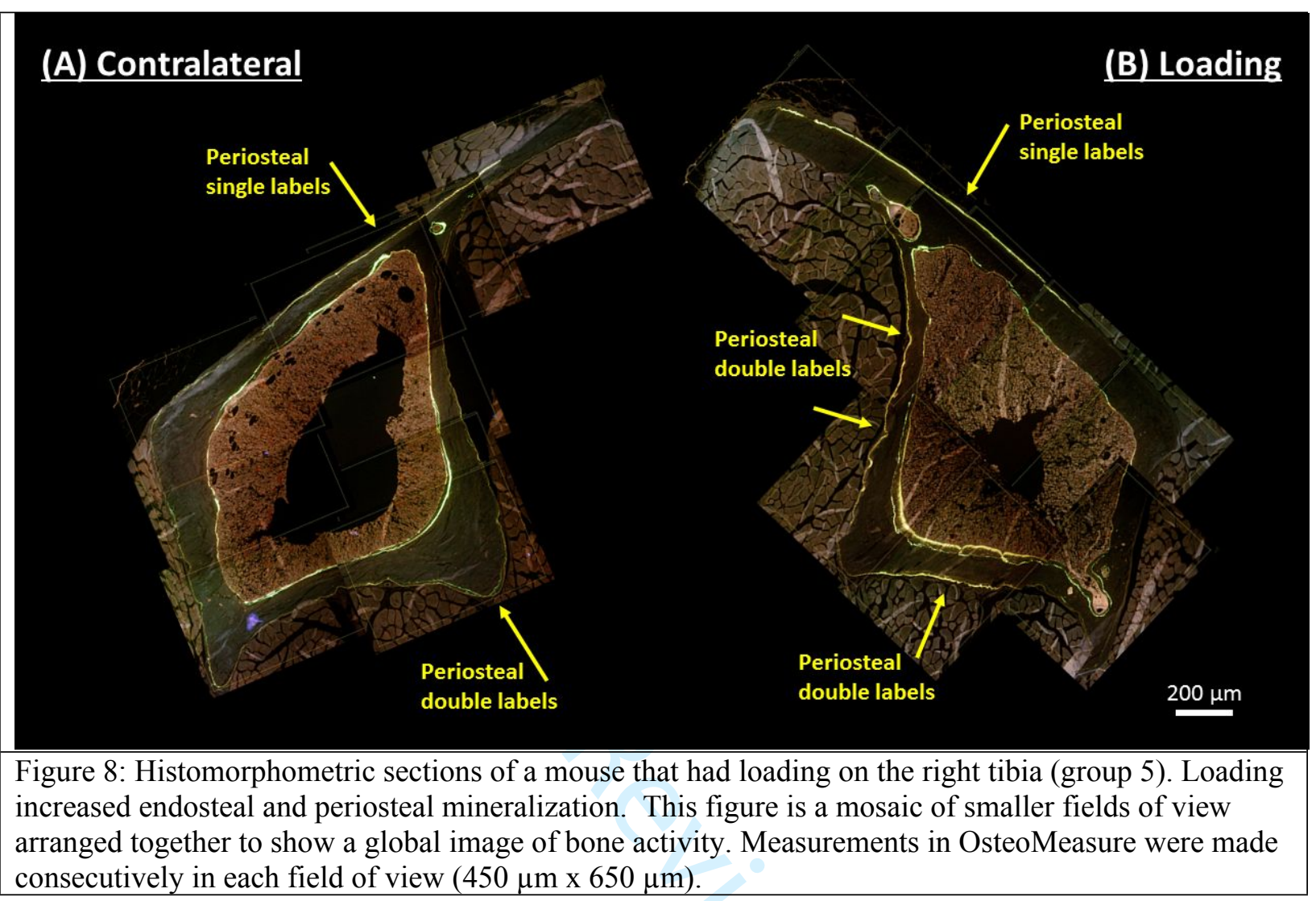




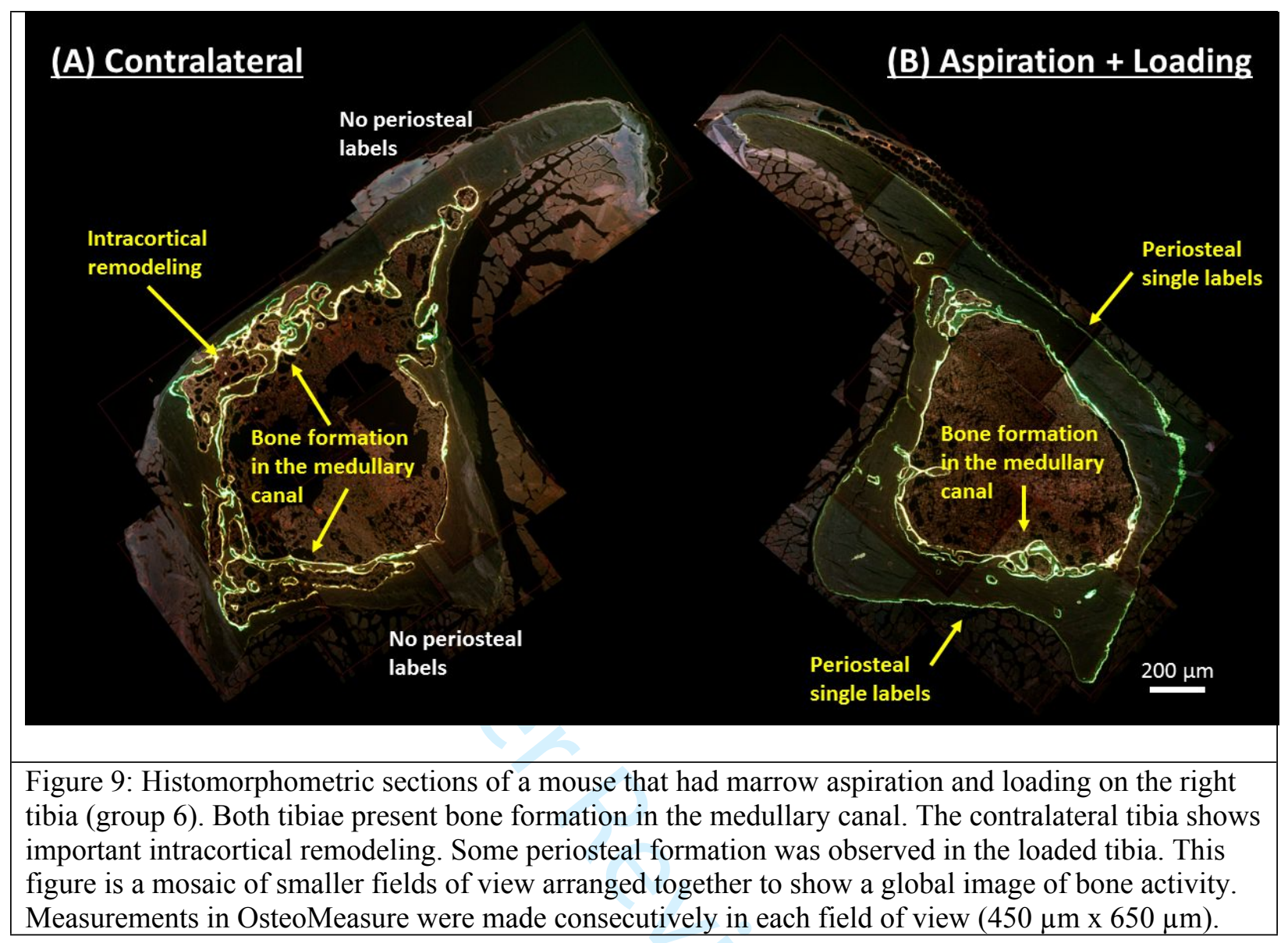




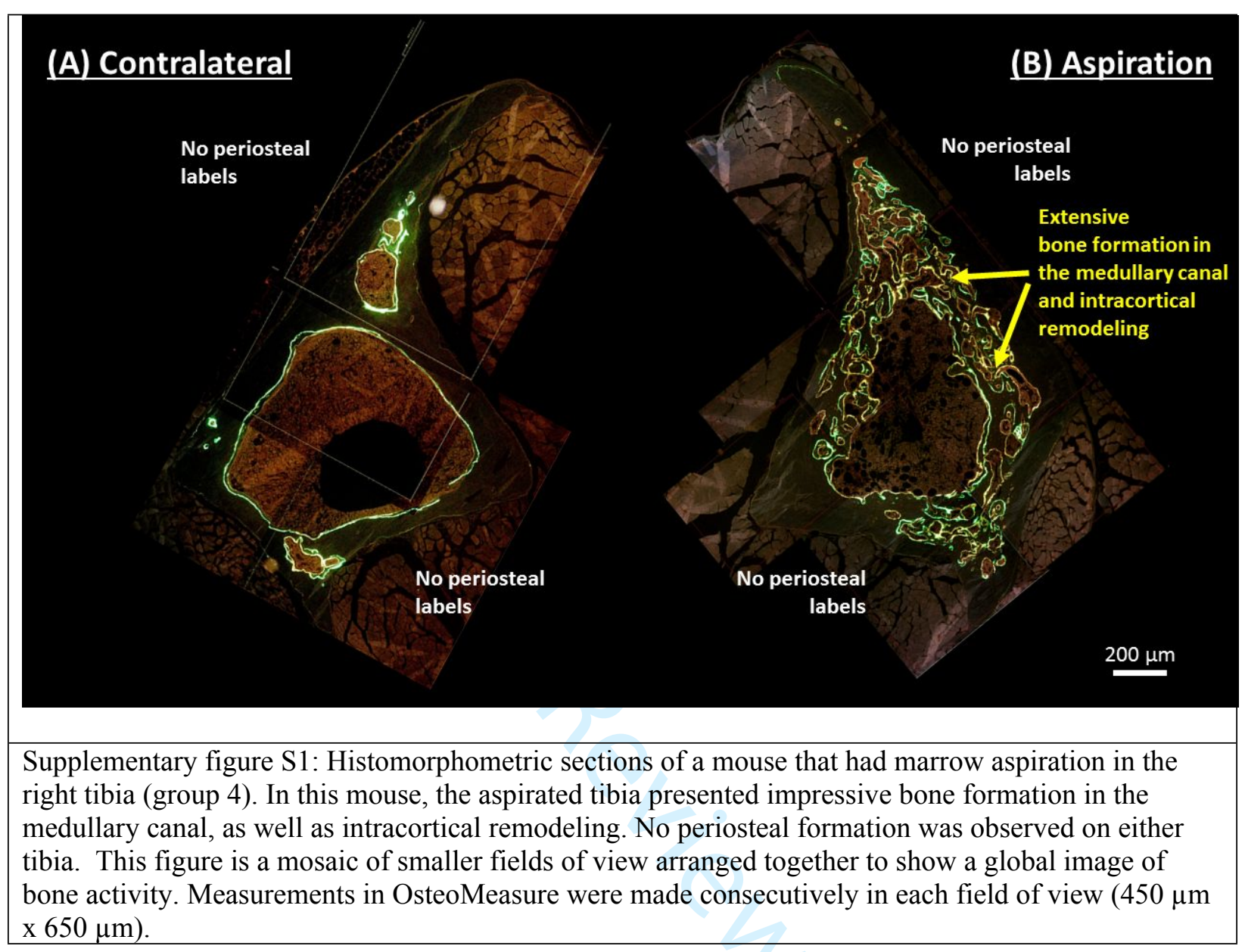


(1) 1 week

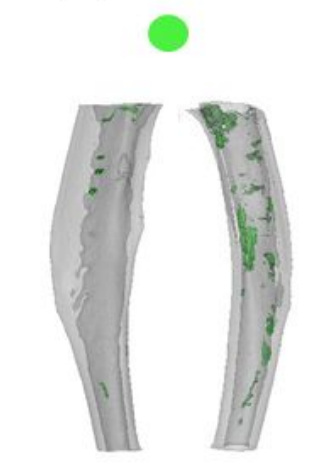

contra. aspi.
(2) 2 weeks

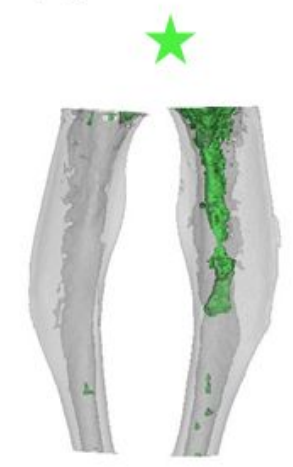

contra. aspi.
(3) 4 weeks

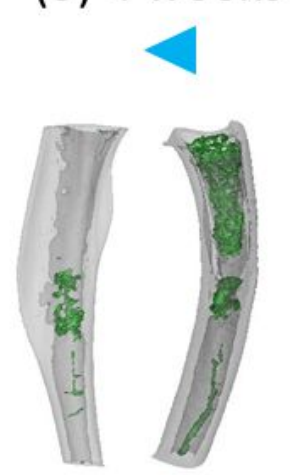

contra. aspi.
(4) 6 weeks

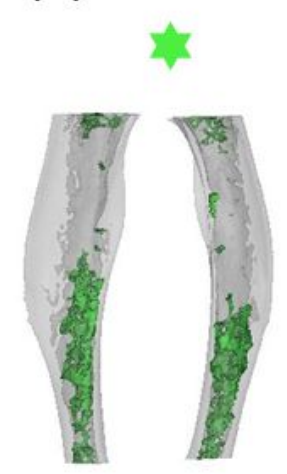

\section{Cortical bone}

"Intramedullary" bone

Supplementary figure S2: Examples of the distribution in intramedullary bone following marrow aspiration. These samples are not representative, and quantitative representation for all samples and variability can be seen on Figure 5 . The samples displayed here are identified with same markers as on Figure 5. 


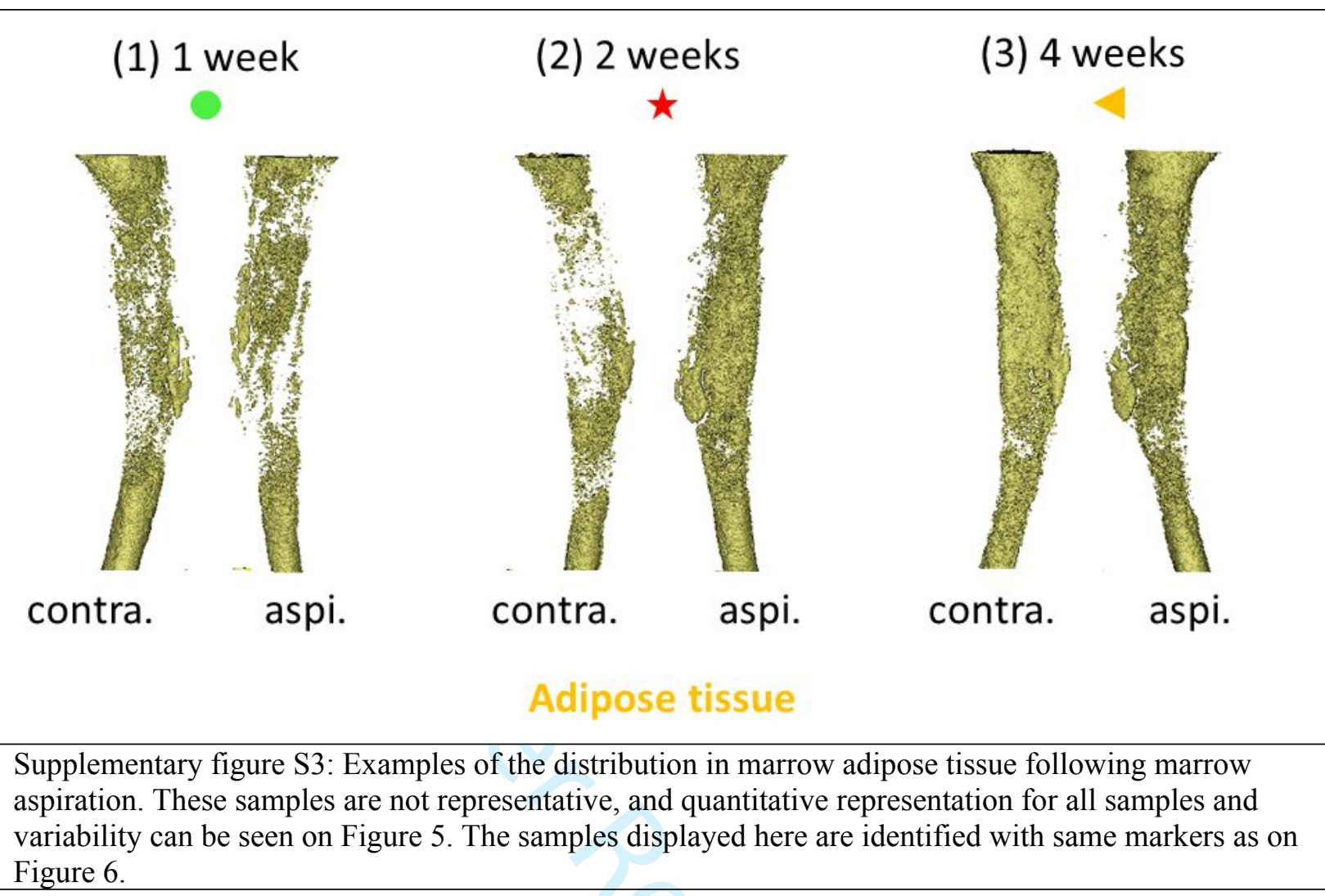

515 


\begin{tabular}{|c|c|c|c|c|c|c|c|c|c|c|c|c|c|c|c|}
\hline \multicolumn{16}{|c|}{ DYNAMIC HISTOMORPHOMETRY } \\
\hline \multicolumn{2}{|l|}{ MS (mm) } & \multicolumn{7}{|c|}{ Non-periosteal } & \multicolumn{7}{|c|}{ Periosteal } \\
\hline \multirow{5}{*}{ A $\begin{array}{c}\text { Wilcoxon } \\
\text { signed- } \\
\text { rank tests }\end{array}$} & \multirow{5}{*}{$\begin{array}{l}\text { (4) aspiration } \\
\text { (5) loading } \\
\text { (6) aspi+loading }\end{array}$} & \multicolumn{3}{|c|}{ left } & \multicolumn{3}{|c|}{ right } & \multirow{2}{*}{$p$-value } & \multicolumn{3}{|c|}{ left } & \multicolumn{3}{|c|}{ right } & \multirow{2}{*}{$p$-value } \\
\hline & & \multicolumn{2}{|c|}{ mean \pm std } & median & \multicolumn{2}{|c|}{ mean \pm std } & median & & \multicolumn{2}{|c|}{ mean \pm std } & median & \multicolumn{2}{|c|}{ mean \pm std } & median & \\
\hline & & \multirow{3}{*}{\multicolumn{2}{|c|}{$\begin{array}{l}2.77 \pm 0.83 \\
2.98 \pm 0.41 \\
3.21 \pm 1.89\end{array}$}} & 2.56 & \multirow{2}{*}{\multicolumn{2}{|c|}{$\begin{array}{l}4.23 \pm 3.11 \\
3.81 \pm 1.44\end{array}$}} & 3.41 & 0.156 & \multicolumn{2}{|c|}{$0.36 \pm 0.22$} & 0.45 & \multicolumn{2}{|c|}{$0.70 \pm 1.18$} & 0.19 & 1.000 \\
\hline & & & & 2.90 & & & 3.14 & 0.219 & $2.02 \pm$ & 1.07 & 1.88 & $3.23 \pm$ & 0.39 & 3.20 & 0.078 \\
\hline & & & & 2.90 & $3.30 \pm$ & 0.89 & 2.98 & 0.844 & $0.43 \pm$ & 0.54 & 0.22 & $2.08 \pm$ & 1.30 & 1.94 & 0.016 \\
\hline Kruskal- & & $p$-value & $\begin{array}{l}\text { post } \\
\text { p-va }\end{array}$ & $\begin{array}{l}\text { st-hoc } \\
\text { values }\end{array}$ & $\mathrm{p}$-value & $\begin{array}{c}\text { pos } \\
p-v\end{array}$ & $\begin{array}{l}\text { st-hoc } \\
\text { values }\end{array}$ & & $p$-value & $\begin{array}{l}p o s \\
p-v\end{array}$ & $\begin{array}{l}\text { st-hoc } \\
\text { values }\end{array}$ & $p$-value & $\begin{array}{l}\text { pos } \\
\mathrm{p}-\mathrm{v}\end{array}$ & $\begin{array}{l}\text { st-hoc } \\
\text { values }\end{array}$ & \\
\hline Wallis & & & & & & & & & & $4 \vee 5:$ & 0.004 & & 4 v 5: & 0.007 & \\
\hline tests & & 0.662 & & & 0.867 & & & & 0.005 & $4 \vee 6:$ & 0.536 & 0.009 & $4 \vee 6:$ & 0.072 & \\
\hline & & & & & & & & & & $5 \vee 6:$ & 0.004 & & $5 \vee 6:$ & 0.040 & \\
\hline $\operatorname{MAR}(\mu \mathrm{m} / \mathrm{d}$ & & & & & n-periost & teal & & & & & & Periosteal & & & \\
\hline Wilcoxon & & mean \pm & $\begin{array}{l}\text { left } \\
\text { std }\end{array}$ & median & mean \pm & $\begin{array}{l}\text { right } \\
\pm \text { std }\end{array}$ & median & $p$-value & mean \pm & $\begin{array}{r}\text { left } \\
\pm \text { std } \\
\end{array}$ & median & mean \pm & $\begin{array}{l}\text { right } \\
\pm \text { std } \\
\end{array}$ & median & $p$-value \\
\hline A signed- & (4) aspiration & $0.79 \pm$ & 0.13 & 0.82 & $0.89 \pm$ & 0.13 & 0.89 & 0.031 & $0.14 \pm$ & 0.20 & 0.00 & $0.26 \pm$ & 0.33 & 0.26 & 0.625 \\
\hline rank tests & (5) loading & $1.08 \pm$ & 0.45 & 1.04 & $1.65 \pm$ & 1.17 & 1.47 & 0.078 & $0.54 \pm$ & 0.23 & 0.55 & $1.62 \pm$ & 1.58 & 1.08 & 0.016 \\
\hline & (6) aspi+loading & $0.85 \pm$ & 0.17 & 0.91 & $1.28 \pm$ & 0.39 & 1.15 & 0.008 & $0.10 \pm$ & 0.16 & 0.00 & $0.69 \pm$ & 0.58 & 0.50 & 0.016 \\
\hline Kruskal- & & $\mathrm{p}$-value & $\begin{array}{l}\text { post } \\
\text { p-va }\end{array}$ & $\begin{array}{l}\text { st-hoc } \\
\text { values }\end{array}$ & $\mathrm{p}$-value & & $\begin{array}{l}\text { st-hoc } \\
\text { values }\end{array}$ & & $p$-value & $\begin{array}{l}\text { pos } \\
\text { p-v }\end{array}$ & $\begin{array}{l}\text { st-hoc } \\
\text { values }\end{array}$ & $p$-value & $\begin{array}{l}\mathrm{pos} \\
\mathrm{p}-\mathrm{v}\end{array}$ & $\begin{array}{l}\text { st-hoc } \\
\text { values }\end{array}$ & \\
\hline Wallis & & & & & & 4 v 5: & 0.026 & & & 4 v 5: & 0.006 & & 4 v 5: & 0.002 & \\
\hline tests & & 0.209 & & & 0.023 & $4 \vee 6:$ & 0.014 & & 0.004 & $4 \vee 6:$ & 0.736 & 0.005 & $4 \vee 6:$ & 0.042 & \\
\hline & & & & & & $5 \vee 6:$ & 0.536 & & & $5 \vee 6:$ & 0.002 & & 5 v $6:$ & $: 0.054$ & \\
\hline BFR $(\mathrm{mm} . \mu \mathrm{m}$ & n/day) & & & No & n-periost & teal & & & & & & Periosteal & & & \\
\hline & & & left & & & right & & & & left & & & right & & \\
\hline Wilcoxon & & mean \pm & & median & mean \pm & \pm std & median & p-value & mean \pm & \pm std & median & mean \pm & \pm std & median & p-value \\
\hline A signed- & (4) aspiration & $2.22 \pm$ & 0.87 & 2.03 & $3.66 \pm$ & 2.55 & 2.73 & 0.016 & $0.07 \pm$ & 0.09 & 0.00 & $0.48 \pm$ & 1.12 & 0.05 & 1.000 \\
\hline rank tests & (5) loading & $3.22 \pm$ & 1.31 & 2.97 & $5.38 \pm$ & 2.14 & 4.64 & 0.016 & $1.22 \pm$ & 0.85 & 0.89 & $5.54 \pm$ & 6.02 & 3.42 & 0.031 \\
\hline & (6) aspi+loading & $2.74 \pm$ & 1.75 & 2.18 & $4.25 \pm$ & 1.75 & 3.86 & 0.109 & $0.10 \pm$ & 0.25 & 0.00 & $1.88 \pm$ & 2.46 & 1.05 & 0.016 \\
\hline Kruskal- & & $p$-value & $\begin{array}{l}\text { post } \\
\text { p-va }\end{array}$ & $\begin{array}{l}\text { st-hoc } \\
\text { values }\end{array}$ & $\mathrm{p}$-value & $\begin{array}{c}\text { pos } \\
p-v\end{array}$ & $\begin{array}{l}\text { st-hoc } \\
\text { values }\end{array}$ & & $p$-value & $\begin{array}{l}\text { pos } \\
\text { p-ve }\end{array}$ & $\begin{array}{l}\text { st-hoc } \\
\text { values }\end{array}$ & $p$-value & pos & $\begin{array}{l}\text { st-hoc } \\
\text { values }\end{array}$ & \\
\hline Wallis & & & & & & & & & & $4 \vee 5:$ & 0.004 & & 4 v 5: & 0.004 & \\
\hline tests & & 0.375 & & & 0.070 & & & & 0.002 & $4 \vee 6:$ & 0.736 & 0.005 & $4 \vee 6:$ & $: 0.057$ & \\
\hline & & & & & & & & & & $5 \vee 6:$ & 0.001 & & 5 v $6:$ & 0.021 & \\
\hline
\end{tabular}

Table 1 - Dynamic histomorphometry. MS = mineralizing surface, $\mathrm{MAR}=$ mineral apposition rate, $\mathrm{BFR}=$ bone formation rate.

(A) Wilcoxon signed-rank tests, comparing right to left tibiae within each group. Marrow aspiration alone (group 4) promoted non-periosteal bone formation in the right tibia, compared to the left. Loading alone (group 5) promoted periosteal and non-periosteal bone formation in the right tibia, compared to the left. When marrow aspiration and loading were combined (group 6), bone formation was increased in the periosteal and non-periosteal compartments in the right tibia, compared to the left.

(B) p-values for Kruskal-Wallis (KW) tests, comparing values across groups, with the null hypothesis that distributions area equal. If significance was found with the Kruskal-Wallis test $(p<0.05)$, post-hoc analysis was run with multiple comparisons (group 4 vs 5 , group 4 vs 6 , and group 5 vs 6 ), using Wilcoxon rank-sum tests and the Bonferroni correction, with the null hypothesis that distributions are equal.

In mice that had marrow aspiration (groups 4 and 6), periosteal bone formation was lower in the contralateral (left) tibia, compared to mice that had loading alone (group 5). Mice that had loading (groups 5 and 6) had higher periosteal and non-periosteal bone formation in the right tibia, compared to mice that had aspiration alone (group 
4). Loading alone (group 5) promoted more periosteal bone formation in the right tibia, compared to mice that had aspiration + loading (group 6).

525

526

527

528 


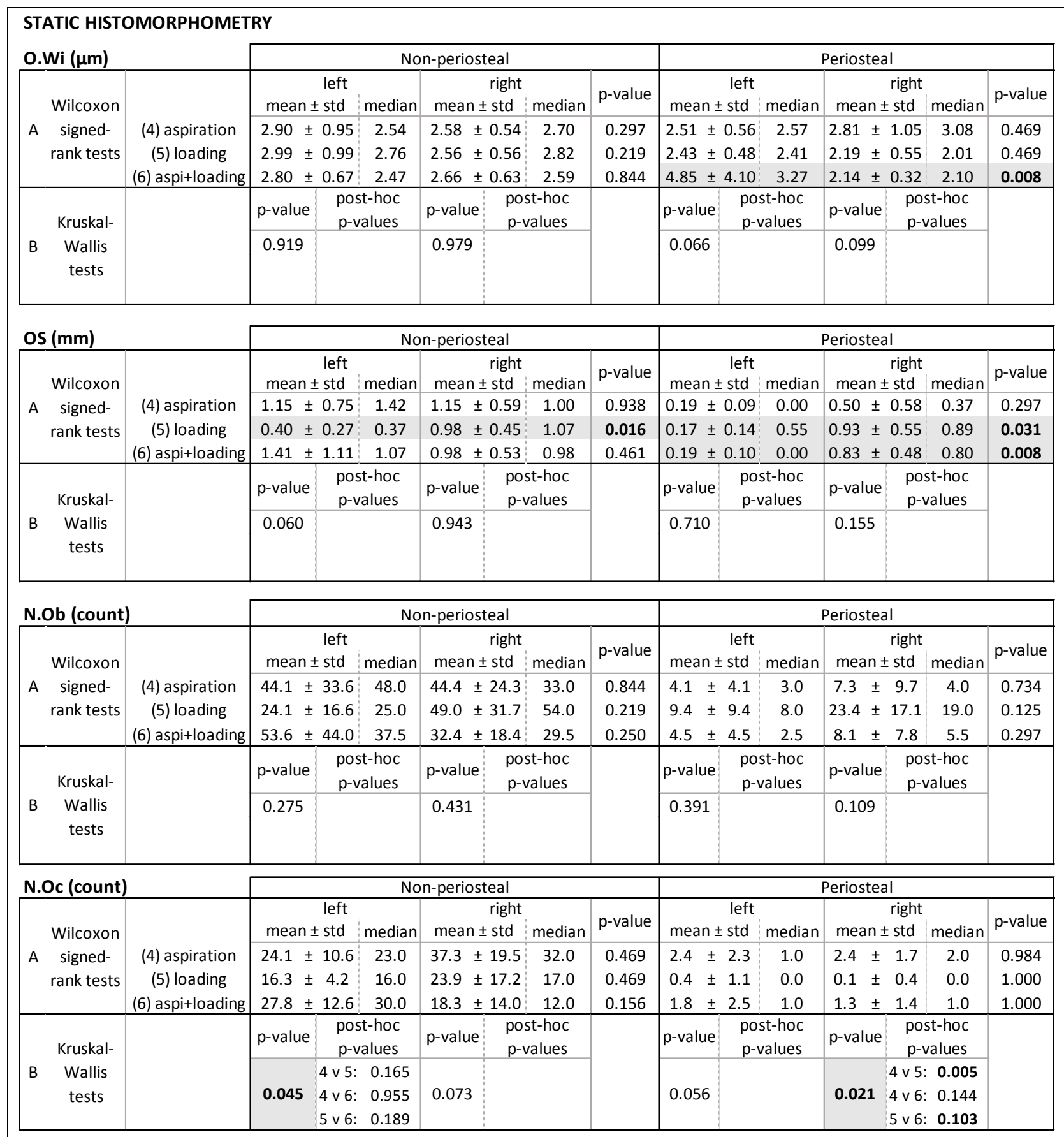

Table 2 - Static histomorphometry. O.Wi $=$ osteoid width, $\mathrm{OS}=$ osteoid surface, $\mathrm{N} . \mathrm{Ob}=$ number of osteoblasts, N.Oc $=$ number of osteoclasts.

(A) Wilcoxon signed-rank tests, comparing right to left tibiae within each group. Loading alone (group 5) increased periosteal and non-periosteal osteoid surface in the right tibia, compared to the left. Aspiration + loading (group 6) increased periosteal osteoid surface and width in the right tibia, compared to the left.

(B) p-values for Kruskal-Wallis (KW) tests, comparing values across groups, with the null hypothesis that distributions area equal. If significance was found with the Kruskal-Wallis test $(p<0.05)$, post-hoc analysis was run with multiple comparisons (group 4 vs 5 , group 4 vs 6 , and group 5 vs 6), using Wilcoxon rank-sum tests and the Bonferroni correction, with the null hypothesis that distributions are equal. Mice that had aspiration alone (group 4) had more periosteal osteoclasts in the right tibia, compared to mice that had loading alone (group 5). 
530

531

URL: http:/mc.manuscriptcentral.com/gcts Email: ICTS-peerreview@journals.tandf.co.uk 


\section{Supplementary Table}

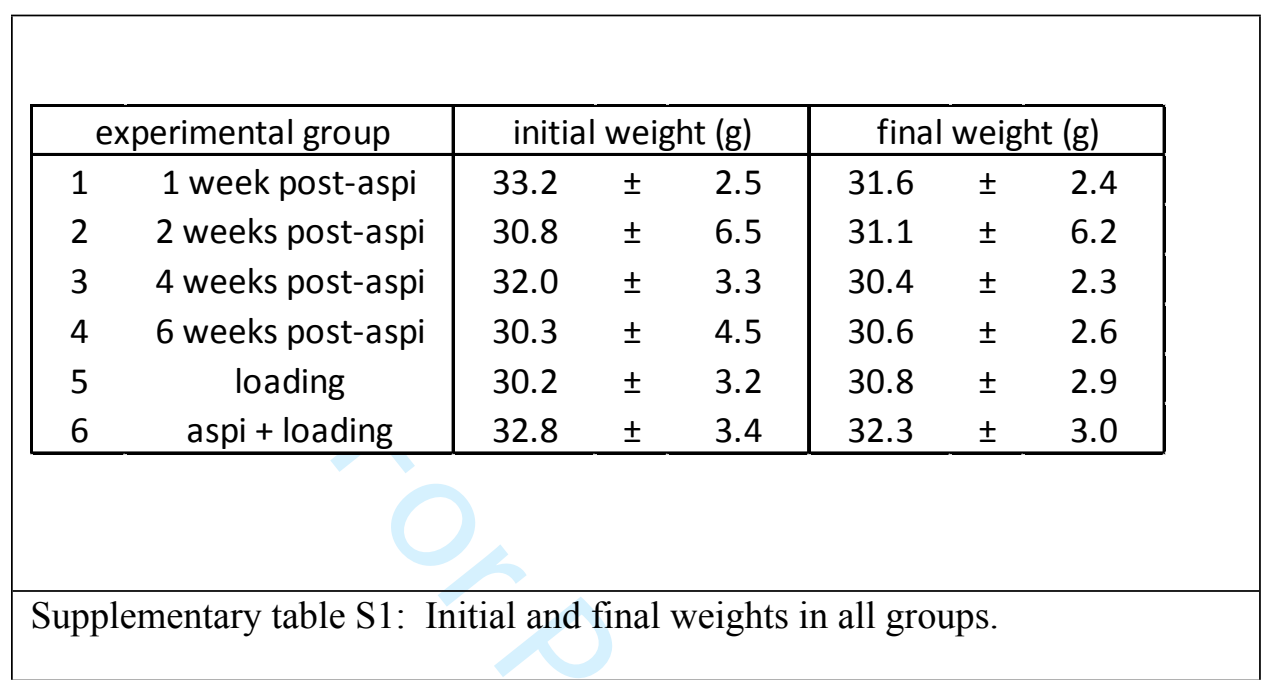

533

534

535

536 


\section{Supplementary methods: section preparation for histomorphometry}

538 We did not deplasticize slides for dynamic histomorphometry. Instead, slides were dipped three times in

539 toluene (3 seconds for each dip) and mounted with toluene-based mounting media (Thermo Scientific,

540 4112). For static histomorphometry, sections were deplasticized with two successive baths in acetone (10

541 minutes for each bath, second acetone bath must be fresh), followed by a bath in $70 \%$ ethanol for 3

542 minutes and a bath in distilled water for 3 minutes.

543 Toluidine blue staining: Sections were stained with toluidine blue to identify osteoblasts and osteoid

544 (Skingle and Compston, 2011). Toluidine blue buffer was prepared with $1.58 \mathrm{~g}$ citric acid (Sigma,

545

546

547

548

549

550

551

552

553

554

555

556

557

558

559

560

561

251275, MW 192.12), $0.75 \mathrm{~g}$ sodium phosphate dibasic (Fisher, 3828-01, FW 141096), $1000 \mathrm{ml}$ distilled water. The buffer can be used for a month. A $2 \%$ toluidine blue staining solution was prepared with $2 \mathrm{~g}$ toluidine blue (Sigma, 198161-25g) and $100 \mathrm{ml}$ of buffer. Solution was stirred for several hours, and filtered through Whatman filter paper. $\mathrm{pH}$ was adjusted to 3.7 before each use (staining solution was changed every 6 months). Sections were immersed in staining solution for 3 minutes, rinsed in buffer for 3-5 seconds, air dried, quickly dipped in butanol, and supplied with a coverslip using toluene-based mounting media (Thermo Scientific, 4112).

TRAP staining: Following deplasticizing, sections were incubated in $0.2 \mathrm{M}$ acetate buffer for one hour at $37^{\circ} \mathrm{C}$. Close to the end of incubation time, TRAP solution was prepared in acetate buffer in the following order. (1) $1000 \mathrm{ml}$ of $0.2 \mathrm{M}$ acetate buffer with $16.4 \mathrm{mg}$ sodium acetate (Sigma, S7545, FW 82.03) and $11.6 \mathrm{mg}$ sodium tartrate dibasic dehydrate (Sigma, 228729, FW 230.1), stirred until dissolved and adjusted $\mathrm{pH}$ to 5.0 with acetic acid. (2) TRAP staining solution with $12.5 \mathrm{ml}$ of $0.2 \mathrm{M}$ acetate buffer, 6.25 mg of Naphthol AS-MX phosphate (Sigma, N4875), and 13.75 mg Fast Red TR salt (Sigma, F6760). When section incubation was over, slides were removed from $0.2 \mathrm{M}$ acetate buffer. Sections were incubated in TRAP staining solution in humidity dish, with TRAP solution dropped on the top of tissue sections. Sections were incubated for $\sim 2$ hours at $37^{\circ} \mathrm{C}$, monitoring after the first half hour, until osteoclasts were bright red. The reaction was stopped before staining of the background occurred. Slides 
562 were rinsed in distilled water. Sections were counterstained for 15 seconds in toluidine blue solution, then 563 washed by dipping several times in toluidine blue buffer and distilled water. Sections were air-dried and 564 mounted with Histomount (HS-103, National Diagnostics) diluted 3:1 with Histo-Clear (HS-200,

565 National Diagnostics).

566 Reference: Skingle, Linda, and Juliet Compston. "Bone histomorphometry." Vitamin D. Academic Press, 567 2011. 845-859.

568

569

570 


\section{Supplementary analysis of intracortical remodeling:}

572 We analyzed the amount of intracortical remodeling using a semi-quantitative score (because it is difficult

573 to discriminate intramedullary / endosteal / intracortical parameters). We divided each section into 4

574 quarters (posterior cortex, lateral cortex, anterior-medial cortex, and posterior-medial cortex) (as

575 described in [32]). For each cortex quarter, we attributed a grade: 0 for no intracortical remodeling, 0.5

576 for some intracortical remodeling (less than $10 \%$ of the surface), 1 for important remodeling. We then

577 added up this score on all 4 quarters to reach a grade from 0 to 4 (with increments of 0.5 ). We tested the

578 distribution with Kolmogorov-Smirnov tests and found that distributions were normal. We then

579 compared left and right tibiae within a group using paired t-tests, with the null hypothesis that left and

580 right tibiae had equal means. All p-values were higher than 0.05 . We concluded that, within a group,

581 there was no difference in intracortical remodeling between left and right tibia. Even some of the

582 unloaded tibiae of mice without aspiration presented intracortical remodeling.

\begin{tabular}{|c|c|c|c|c|c|c|}
\hline & \multicolumn{2}{|c|}{ left } & \multicolumn{3}{|c|}{ right } & \multirow{2}{*}{$\begin{array}{c}\text { paired t-test } \\
\text { p-value }\end{array}$} \\
\hline & mean & std & mean & \pm & std & \\
\hline (4) 6 weeks aspiration & 0.71 & 0.59 & 1.29 & \pm & 1.16 & 0.356 \\
\hline (5) loading & 0.36 & 0.35 & 1.14 & \pm & 1.12 & 0.130 \\
\hline (6) aspiration + loading & 1.19 & 1.09 & 0.75 & \pm & 0.35 & 0.247 \\
\hline p-value for one-way ANOVA & & & & 0.5 & & \\
\hline
\end{tabular}

Intracortical remodeling scores in the left and right tibiae. Paired t-tests were used to test the null hypothesis that means are equal in the left and right tibiae within each group. One-way ANOVA tests were also used to test the null hypothesis that means are equal across groups within left tibiae, and within right tibiae.

We also looked for correlations between the intracortical remodeling score and the periosteal bone

584 formation in the left contralateral tibiae, with the idea that perhaps the more intracortical remodeling, the and the periosteal mineralizing surface, and found no correlation $(\mathrm{p}>0.05)$. 


\begin{tabular}{|l|cc|cc|cc|}
\hline \multirow{2}{*}{} & \multicolumn{2}{|c|}{ Ps.MS } & \multicolumn{2}{c|}{ Ps.MAR } & \multicolumn{2}{c|}{ Ps.BFR } \\
& $\mathrm{R}^{2}$ & $\mathrm{p}$-value & $\mathrm{R}^{2}$ & $\mathrm{p}$-value & $\mathrm{R}^{2}$ & $\mathrm{p}$-value \\
\hline (4) 6 weeks aspiration & 0.052 & 0.622 & 0.144 & 0.402 & 0.176 & 0.348 \\
(5) loading & 0.001 & 0.952 & 0.185 & 0.335 & 0.018 & 0.776 \\
(6) aspiration + loading & 0.014 & 0.780 & 0.000 & 0.974 & 0.002 & 0.912 \\
\hline
\end{tabular}

Linear regression between intracortical remodeling scores and periosteal dynamic histomorphometry parameters (periosteal mineralizing surface, mineral apposition rate, bone formation rate). 


\section{The ARRIVE Guidelines Checklist}

\section{Animal Research: Reporting In Vivo Experiments}

Carol Kilkenny ${ }^{1}$, William J Browne ${ }^{2}$, Innes C Cuthill ${ }^{3}$, Michael Emerson ${ }^{4}$ and Douglas G Altman ${ }^{5}$

${ }^{1}$ The National Centre for the Replacement, Refinement and Reduction of Animals in Research, London, UK, ${ }^{2}$ School of Veterinary Science, University of Bristol, Bristol, UK, ${ }^{3}$ School of Biological Sciences, University of Bristol, Bristol, UK, ${ }^{4}$ National Heart and Lung Institute, Imperial College London, UK, ${ }^{5}$ Centre for Statistics in Medicine, University of Oxford, Oxford, UK.

\begin{tabular}{|c|c|c|c|}
\hline & ITEM & RECOMMENDATION & $\begin{array}{l}\text { Section/ } \\
\text { Paragraph }\end{array}$ \\
\hline Title & 1 & $\begin{array}{l}\text { Provide as accurate and concise a description of the content of the article } \\
\text { as possible. }\end{array}$ & Yes, title \\
\hline Abstract & 2 & $\begin{array}{l}\text { Provide an accurate summary of the background, research objectives, } \\
\text { including details of the species or strain of animal used, key methods, } \\
\text { principal findings and conclusions of the study. }\end{array}$ & $\begin{array}{l}\text { Yes, } \\
\text { abstract }\end{array}$ \\
\hline \multicolumn{4}{|l|}{ INTRODUCTION } \\
\hline Background & 3 & $\begin{array}{l}\text { a. Include sufficient scientific background (including relevant references to } \\
\text { previous work) to understand the motivation and context for the study, } \\
\text { and explain the experimental approach and rationale. } \\
\text { b. Explain how and why the animal species and model being used can } \\
\text { address the scientific objectives and, where appropriate, the study's } \\
\text { relevance to human biology. }\end{array}$ & $\begin{array}{l}\text { Yes, } \\
\text { throughout } \\
\text { intro }\end{array}$ \\
\hline Objectives & 4 & $\begin{array}{l}\text { Clearly describe the primary and any secondary objectives of the study, or } \\
\text { specific hypotheses being tested. }\end{array}$ & $\begin{array}{l}\text { Yes, last } \\
\text { paragraph } \\
\text { of intro }\end{array}$ \\
\hline \multicolumn{4}{|l|}{ METHODS } \\
\hline Ethical statement & 5 & $\begin{array}{l}\text { Indicate the nature of the ethical review permissions, relevant licences (e.g. } \\
\text { Animal [Scientific Procedures] Act 1986), and national or institutional } \\
\text { guidelines for the care and use of animals, that cover the research. }\end{array}$ & $\begin{array}{l}\text { Yes, } \\
\text { paragraph } \\
2.1\end{array}$ \\
\hline Study design & 6 & $\begin{array}{l}\text { For each experiment, give brief details of the study design including: } \\
\text { a. The number of experimental and control groups. } \\
\text { b. Any steps taken to minimise the effects of subjective bias when } \\
\text { allocating animals to treatment (e.g. randomisation procedure) and when } \\
\text { assessing results (e.g. if done, describe who was blinded and when). } \\
\text { c. The experimental unit (e.g. a single animal, group or cage of animals). } \\
\text { A time-line diagram or flow chart can be useful to illustrate how complex } \\
\text { study designs were carried out. }\end{array}$ & $\begin{array}{l}\text { Yes, } \\
\text { paragraph } \\
2.1 \text { and } \\
\text { time-line } \\
\text { diagrams } \\
\text { in figures } 1 \\
\text { and } 2\end{array}$ \\
\hline $\begin{array}{l}\text { Experimental } \\
\text { procedures }\end{array}$ & 7 & $\begin{array}{l}\text { For each experiment and each experimental group, including controls, } \\
\text { provide precise details of all procedures carried out. For example: } \\
\text { a. How (e.g. drug formulation and dose, site and route of administration, } \\
\text { anaesthesia and analgesia used [including monitoring], surgical } \\
\text { procedure, method of euthanasia). Provide details of any specialist } \\
\text { equipment used, including supplier(s). } \\
\text { b. When (e.g. time of day). } \\
\text { c. Where (e.g. home cage, laboratory, water maze). } \\
\text { d. Why (e.g. rationale for choice of specific anaesthetic, route of } \\
\text { administration, drug dose used). }\end{array}$ & $\begin{array}{l}\text { Yes, } \\
\text { paragraphs } \\
2.2-2.5\end{array}$ \\
\hline $\begin{array}{l}\text { Experimental } \\
\text { animals }\end{array}$ & 8 & $\begin{array}{l}\text { a. Provide details of the animals used, including species, strain, sex, } \\
\text { developmental stage (e.g. mean or median age plus age range) and } \\
\text { weight (e.g. mean or median weight plus weight range). } \\
\text { b. Provide further relevant information such as the source of animals, } \\
\text { international strain nomenclature, genetic modification status (e.g. } \\
\text { knock-out or transgenic), genotype, health/immune status, drug or test } \\
\text { naïve, previous procedures, etc. }\end{array}$ & $\begin{array}{l}\text { Yes, } \\
\text { paragraph } \\
2.1 \text { and } \\
\text { supplemen } \\
\text { tary table } \\
2.1\end{array}$ \\
\hline
\end{tabular}




\begin{tabular}{|c|c|c|c|}
\hline $\begin{array}{l}\text { Housing and } \\
\text { husbandry }\end{array}$ & 9 & $\begin{array}{l}\text { Provide details of: } \\
\text { a. Housing (type of facility e.g. specific pathogen free [SPF]; type of cage or } \\
\text { housing; bedding material; number of cage companions; tank shape and } \\
\text { material etc. for fish). } \\
\text { b. Husbandry conditions (e.g. breeding programme, light/dark cycle, } \\
\text { temperature, quality of water etc for fish, type of food, access to food } \\
\text { and water, environmental enrichment). } \\
\text { c. Welfare-related assessments and interventions that were carried out } \\
\text { prior to, during, or after the experiment. }\end{array}$ & $\begin{array}{l}\text { Yes, } \\
\text { paragraph } \\
2.1\end{array}$ \\
\hline Sample size & 10 & $\begin{array}{l}\text { a. Specify the total number of animals used in each experiment, and the } \\
\text { number of animals in each experimental group. } \\
\text { b. Explain how the number of animals was arrived at. Provide details of any } \\
\text { sample size calculation used. } \\
\text { c. Indicate the number of independent replications of each experiment, if } \\
\text { relevant. }\end{array}$ & $\begin{array}{l}\text { Yes, } \\
\text { paragraph } \\
2.1\end{array}$ \\
\hline $\begin{array}{l}\text { Allocating } \\
\text { animals to } \\
\text { experimental } \\
\text { groups }\end{array}$ & 11 & $\begin{array}{l}\text { a. Give full details of how animals were allocated to experimental groups, } \\
\text { including randomisation or matching if done. } \\
\text { b. Describe the order in which the animals in the different experimental } \\
\text { groups were treated and assessed. }\end{array}$ & $\begin{array}{l}\text { Yes, } \\
\text { paragraph } \\
2.1\end{array}$ \\
\hline $\begin{array}{l}\text { Experimental } \\
\text { outcomes }\end{array}$ & 12 & $\begin{array}{l}\text { Clearly define the primary and secondary experimental outcomes assessed } \\
\text { (e.g. cell death, molecular markers, behavioural changes). }\end{array}$ & $\begin{array}{l}\text { Yes, } \\
\text { paragraphs } \\
2.6-2.8\end{array}$ \\
\hline $\begin{array}{l}\text { Statistical } \\
\text { methods }\end{array}$ & 13 & $\begin{array}{l}\text { a. Provide details of the statistical methods used for each analysis. } \\
\text { b. Specify the unit of analysis for each dataset (e.g. single animal, group of } \\
\text { animals, single neuron). } \\
\text { c. Describe any methods used to assess whether the data met the } \\
\text { assumptions of the statistical approach. }\end{array}$ & $\begin{array}{l}\text { Yes, } \\
\text { paragraph } \\
2.9 \\
\text { (statistical } \\
\text { analysis) }\end{array}$ \\
\hline \multicolumn{4}{|l|}{ RESULTS } \\
\hline Baseline data & 14 & $\begin{array}{l}\text { For each experimental group, report relevant characteristics and health } \\
\text { status of animals (e.g. weight, microbiological status, and drug or test naïve) } \\
\text { prior to treatment or testing. (This information can often be tabulated). }\end{array}$ & $\begin{array}{l}\text { Yes, } \\
\text { supplement } \\
\text { ary table } \\
\text { S1 }\end{array}$ \\
\hline $\begin{array}{l}\text { Numbers } \\
\text { analysed }\end{array}$ & 15 & $\begin{array}{l}\text { a. Report the number of animals in each group included in each analysis. } \\
\text { Report absolute numbers (e.g. } 10 / 20 \text {, not } 50 \%{ }^{2} \text { ). } \\
\text { b. If any animals or data were not included in the analysis, explain why. }\end{array}$ & $\begin{array}{l}\text { Yes, see } \\
\text { legend of } \\
\text { figures } 4-6\end{array}$ \\
\hline $\begin{array}{l}\text { Outcomes and } \\
\text { estimation }\end{array}$ & 16 & $\begin{array}{l}\text { Report the results for each analysis carried out, with a measure of precision } \\
\text { (e.g. standard error or confidence interval). }\end{array}$ & $\begin{array}{l}\text { Yes, see } \\
\text { tables } 1 \\
\text { and } 2\end{array}$ \\
\hline Adverse events & 17 & $\begin{array}{l}\text { a. Give details of all important adverse events in each experimental group. } \\
\text { b. Describe any modifications to the experimental protocols made to } \\
\text { reduce adverse events. }\end{array}$ & $\begin{array}{l}\text { No adverse } \\
\text { events }\end{array}$ \\
\hline \multicolumn{4}{|l|}{ DISCUSSION } \\
\hline $\begin{array}{l}\text { Interpretation/ } \\
\text { scientific } \\
\text { implications }\end{array}$ & 18 & $\begin{array}{l}\text { a. Interpret the results, taking into account the study objectives and } \\
\text { hypotheses, current theory and other relevant studies in the literature. } \\
\text { b. Comment on the study limitations including any potential sources of bias, } \\
\text { any limitations of the animal model, and the imprecision associated with } \\
\text { the results }{ }^{2} \text {. } \\
\text { c. Describe any implications of your experimental methods or findings for } \\
\text { the replacement, refinement or reduction (the 3Rs) of the use of animals } \\
\text { in research. }\end{array}$ & $\begin{array}{l}\text { Yes, in } \\
\text { discussion }\end{array}$ \\
\hline $\begin{array}{l}\text { Generalisability/ } \\
\text { translation }\end{array}$ & 19 & $\begin{array}{l}\text { Comment on whether, and how, the findings of this study are likely to } \\
\text { translate to other species or systems, including any relevance to human } \\
\text { biology. }\end{array}$ & $\begin{array}{l}\text { Yes, in } \\
\text { conclusion }\end{array}$ \\
\hline Funding & 20 & $\begin{array}{l}\text { List all funding sources (including grant number) and the role of the } \\
\text { funder(s) in the study. }\end{array}$ & $\begin{array}{l}\text { Yes, } \\
\text { included }\end{array}$ \\
\hline
\end{tabular}


1. Kilkenny C, Browne WJ, Cuthill IC, Emerson M, Altman DG (2010) Improving Bioscience Research Reporting: The ARRIVE Guidelines for Reporting Animal Research. PLOS Biol 8(6): e1000412. doi:10.1371/journal.pbio.1000412

2. Schulz KF, Altman DG, Moher D, the CONSORT Group (2010) CONSORT 2010 Statement: updated guidelines for reporting paralle group randomised trials. BMJ 340:0332. 